\title{
Pharmacological Treatment of Osteoporosis
}

\author{
Jorge Malouf-Sierra ${ }^{1}$ and Roberto Güerri-Fernández ${ }^{2}$ \\ 1 Universitat Autònoma de Barcelona, \\ Hospital de la Santa Creu i Sant Pau Barcelona, \\ ${ }^{2}$ Universitat Autònoma de Barcelona, \\ IMIM-Hospital del Mar Barcelona, \\ Spain
}

\section{Introduction}

Osteoporosis can be classified into two big categories, clinical osteoporosis and densitometric osteoporosis. Clinical osteoporosis involves a fragility fracture, and no densitometry is needed to start treatment. Densitometric osteoporosis is defined by means of a bone mineral density assessment. Treatment should be considered depending on the global fracture risk, and taking the densitometric results into account.

The first step in the pharmacological treatment of osteoporosis is to identify whether it is a primary disease or whether the bone mass loss is secondary to another disease. In the case of a secondary osteoporosis, treatment of the primary disease is the most important step. Pharmacological treatment should then be considered if the fracture risk is too high. The purpose of pharmacological treatment in osteoporosis is to reduce the risk of fracture. According to the World Health Organization's more than half of the patients suffering a fragility fracture do not have densitometric osteoporosis. (Siris et al., 2004) When any medication is started for osteoporosis treatment it must be remembered that this illness will require treatment for a long time and that the drug has to be given in conjunction with advise regarding lifestyle changes. It is therefore imperative to evaluate and make decisions based on issues such as cost, evaluation of cost-efficiency, and patient adaptability to drug safety.

\section{Antiresorptives}

\subsection{Calcitonin}

Calcitonin is a 32 amino acid polypeptide. It binds to osteoclasts and inhibits bone resorption. Calcitonins from many species are effective in humans, but salmon calcitonin is the most widely used. It is extremely potent in humans due to its higher affinity (forty times that of human calcitonin) for the human calcitonin receptor. The only other calcitonin clinically used is human calcitonin, less potent but also less antigenic than salmon calcitonin. (Carstens \& Feinblatt, 1991) It can be administered by intramuscular, intravenous or nasal route. The bioavailability of nasal salmon calcitonin is only about 25 percent that of intramuscular calcitonin; thus, the biological effect of 50 international units (IU) of intramuscular salmon calcitonin is comparable to that of $200 \mathrm{IU}$ of nasal salmon calcitonin. (Overgaard et al., 1991) 


\subsubsection{Clinical data}

There is evidence that calcitonin is effective in the treatment of established osteoporosis. In one study of calcitonin in osteoporosis, 208 elderly osteopenic women were treated with calcium and either intranasal placebo, or 50, 100, or $200 \mathrm{IU}$ of daily salmon calcitonin for two years. Mean spine bone mineral density (BMD) was increased by salmon calcitonin in a dose-dependent manner, and a maximum effect was seen with the $200 \mathrm{IU}$ dose. (Overgaard et al., 1992)

The largest clinical trial with calcitonin for the treatment of osteoporosis was a five-year trial comprising 1,255 women with a lumbar spine $\mathrm{T}$ score of $<-2$ and at least one vertebral fracture. They were randomly assigned to placebo or 100, 200, or 400 IU of intranasal calcitonin per day. There was a small increase in spine BMD (1\% to $1.5 \%)$ in all groups. The risk of vertebral fracture was significantly lower than placebo only in the group taking 200 IU per day, and the risk of non-vertebral fractures was significantly lower than placebo only in the group taking 100 IU per day. Thus, the beneficial effect of nasal calcitonin on vertebral BMD and vertebral fracture risk was small and inconsistent. (Chesnut et al., 2000)

Nowadays calcitonin is not a current therapy for osteoporosis. It has been displaced by other treatments. However, one beneficial short-term effect of calcitonin therapy is pain reduction in patients who have sustained a fracture. In one study, looking for pain effect of calcitonin, 56 osteoporotic women who sustained an atraumatic vertebral fracture were randomly assigned to treatment with placebo or $100 \mathrm{IU}$ of intramuscular salmon calcitonin daily for two weeks. Mean pain scores and analgesic consumption in the calcitonin group were significantly lower than in the placebo group by the fourth day. Similar benefits on bone pain have been observed in several other small, randomized trials of parental and nasal calcitonin. The ability to relieve pain may represent a truly distinguishing feature from other drugs used in the treatment of osteoporosis and maybe today it is one of its main indications. (Lyritis et al., 1991)

\subsubsection{Adverse effects}

The most frequent adverse effects of calcitonin appear during or shortly after its parenteral administration: digestive disorders, nausea, vomiting, abdominal pains, diarrhea, vasomotor disorders or facial flushing among others. Allergy to calcitonin is possible but exceptional. Thus, calcitonin may be the antiresorptive agent of choice in patients with pain from an acute osteoporotic fracture. Why pain relief occurs is not well understood; one possibility is a rise in endorphin levels induced by calcitonin.

\subsection{Hormonal replacement therapy (HRT)}

The HRT is a treatment option that includes different estrogen doses, in combination, or not, with progestagens. Hormonal replacement therapy is described in detail in another chapter. Therefore, in this chapter we are just going to make a review of the antifracture efficacy of HRT along with the safety data from different meta-analysis, systematic reviews and clinical guides.

\subsubsection{Hormone replacement therapy (HRT) for fracture prevention}

The estimations of fracture risk, derived from the principal cohort studies of postmenopausal women, using HRT for long periods of time, show a significant vertebral fracture risk reduction ( $\mathrm{RR}=0.6 ; \mathrm{CI} 95 \%$ : 0.36 to 0.99$)$ and wrist fracture risk reduction 
$(\mathrm{RR}=0.39 ; \mathrm{CI} 95 \%$ : 0.24 to 0.64$)$, but a non-significant hip fracture risk reduction $(\mathrm{RR}=0.64 ; \mathrm{CI}$ 95\%: 0.32 to 1.04). The WHI study (Women's Health Initiative), a randomized clinical trial (RCT) that evaluated postmenopausal women randomized to combined HRT (combined equine estrogen $0.625 \mathrm{mg}$ daily plus medroxyprogesterone $2.5 \mathrm{mg}$ daily) or placebo, demonstrated, after 5.2 years of treatment, a hip fracture risk reduction of $34 \%$ (hazard ratio $[\mathrm{HR}]=0.66$; CI 95\%: 0.45 to 0.98$)$, of clinical vertebral fractures of $34 \%(\mathrm{HR}=0.66 ; \mathrm{CI} 95 \%: 0.44$ to 0.98 ) and a reduction in any fracture of $24 \%$ (HR=0.76; CI $95 \%: 0.69$ to 0.85 ). (Rossouw et al., 2002; Cauley et al., 2003) In the same study, the branch using estrogen alone showed similar results, but it was suspended due to an unfavorable risk benefit ratio. (Anderson et al., 2004) In two meta-analysis of RCTs a reduction of $27 \%$ (RR=0.73; CI 95\%: 0.56 to 0.94) in non-vertebral fractures and a tendency towards the decrease of vertebral fractures $(R R=0.66$; CI 95\%: 0.41 to 1.07) was described. (MacLean et al., 2008) Nevertheless, from the HERS (The Heart and Estrogen + Progestin Replacement Study) RCT and from the cohort followed, the HERS II study (Hulley et al., 1998), no reduction of the risk of hip fractures or of other locations ( $R R=1.04$; CI 95\%: 0.87 to 1.25 ) in women with cardiovascular disease history, could be demonstrated. (Cauley et al., 2001)

Another meta-analysis, which included information from two publications of the WHI study (women with and without osteoporosis, without DMO measurements) found a reduction of $25 \%$ of the relative risk of non-vertebral fractures ( $R R=0.75$; CI $95 \%$ : 0.70 to 0.81 ) in a sample of 31,333 patients followed up for a maximum of 7 years and a $36 \%$ relative risk reduction for hip fractures ( $R R=0.64$; CI $95 \%$ : 0.49 to 0.84 ) in a sample of 27,347 patients. (Liberman et al., 2006) The British National Institute of Health and Clinical Excellence presented a meta-analysis of RCTs on the efficacy of HRT (with estrogen alone or combined) vs. placebo / not treatment in postmenopausal women or with surgical menopause. (National Institute for Clinical Excellence [NICE], 2008) The results were presented by fracture location and specified the RCT used for the estimation of the relative risk. The results are summarized in table 1 .

\subsubsection{Safety}

\subsubsection{Vascular illness}

A systematic review of five RCTs, studying HRT with estrogen and two with combined HRT estrogen plus progesterone, did not demonstrate significant differences in the incidence of acute coronary events (including acute myocardial infarction) between the group of intervention and the control group. (MacLean et al., 2008) Two of the essays with estrogen and two of combined therapy (estrogen plus progesterone) that reported the incidence of death of cardiac origin did not demonstrate significant differences between the intervention group and control group. Combined results of three essays comparing estrogenic therapy with placebo (Anderson et al., 2004; Mosekilde et al., 2000; Cherry et al., 2002) presented an odds ratio (OR) of 1.34 (IC 95\%: 1.07 to 1.68) for cerebral vascular events. The combined results of the essays that compared combined therapy estrogen plus progesterone with placebo (Rossouw et al., 2002; Hulley et al., 1998), demonstrated a higher risk of ictus (OR=1.28; CI 95\%: 1.05 to 1.57) in the intervention group. Of 4 systematic reviews of observational studies in women receiving HRT (Stampfer et al., 1991; Grady et al., 2002; Barrett-Connor, 1992; Humphrey et al., 2002), three demonstrated an important reduction in the global risk of mortality for acute coronary events. The most recent systematic review, that controlled selection bias of inclusion and analysis, did not show any 
association between the THS and the incidence, and mortality of acute coronary events. (Humphrey et al., 2002)

The WHI primary prevention study showed a significant increase in the risk of acute coronary events $(41 \%)$, beginning the second year of treatment (29 cases in the treatment group, compared with 21 cases for 10.000 women/year in the general population). (Rossouw et al., 2002) This increase was higher in non-mortal coronary events (RR=1.50; CI 95\%: 1.08 to 2.08 ) than in the mortal coronary events ( $R R=1.20$; CI 95\%: 0.58 to 2.50 ). The RCTs of HRT with estrogens alone, in primary prevention as well as in secondary prevention, did not show any benefit on the cerebrovascular illness. (Viscoli et al., 2001) The group of the WHI study with estrogen also showed an increase in the risk of cerebrovascular accidents. (Anderson et al., 2004)

\begin{tabular}{|l|l|l|l|l|}
\hline Fracture Location & Nr of RCTs & $\mathrm{n}$ & RESULTS & References \\
\hline Vertebral fracture & 4 RCTs & 11,842 & $\begin{array}{l}\text { RR=0.55; CI 95\%: } \\
0.46 \text { to 0.66 }\end{array}$ & $\begin{array}{l}\text { (Wimalawansa, 1998; } \\
\text { Mosekilde et al., 2000; } \\
\text { Anderson et al., 1997; } \\
\text { Lufkin et al., 1992) }\end{array}$ \\
\hline Non-vertebral fracture & 3 RCTs & 11,774 & $\begin{array}{l}\text { RR=0.73; CI 95\%: } \\
0.65 \text { to 0.81 }\end{array}$ & $\begin{array}{l}\text { (Wimalawansa, 1998; } \\
\text { Anderson et al., 2003; } \\
\text { Mosekilde et al., 2000) }\end{array}$ \\
\hline Hip fracture & 2 RCTs & 11,745 & $\begin{array}{l}\text { RR=0.63; CI 95\%: } \\
0.42 \text { to 0.93 }\end{array}$ & $\begin{array}{l}\text { (Anderson et al., 2003; } \\
\text { Mosekilde et al., 2000) }\end{array}$ \\
\hline Any type of fracture & 3 RCTs & 11,556 & $\begin{array}{l}\text { RR=0.70; CI 95\%: } \\
0.63 \text { to 0.78 }\end{array}$ & $\begin{array}{l}\text { (Anderson et al., 2003; } \\
\text { Herrington et al., 2000; } \\
\text { Ravn et al., 1999) }\end{array}$ \\
\hline
\end{tabular}

Table 1. Relative risk of fractures in meta-analysis from the NICE

\subsubsection{Venous thrombotic events}

In a systematic review, McLean et al., reported that estrogen treated patients present a higher risk of major venous thromboembolic events (OR=1.36; CI 95\%: 1.01 to 1.86) compared to the placebo group. (MacLean et al., 2008) Another systematic review evaluating the effect of the HRT (estrogen with or without progestagens) included 12 studies ( 3 RCTs, 8 case-control studies and 1 cohort study) and showed an increase in the risk of thromboembolism ( $R R=2.14$; CI $95 \%$ : 1.64 to 2.81). This risk is higher in the first two years of treatment and it is dose dependant. (Miller et al., 2002) The HERS study for secondary prevention showed an increase in the risk of thromboembolism in women with cardiovascular illness. (Hulley et al., 1998; Grady et al., 2002)

\subsubsection{Breast cancer}

A systematic review of 4 RCTs demonstrated that patients treated with estrogens alone present lower risk of breast cancer ( $\mathrm{OR}=0.79$; CI 95\%: 0.66 to 0.93 ) compared to placebo. (MacLean et al., 2008) On the contrary, patients treated with estrogen and progestin present a higher risk of breast cancer (OR=1.28; CI 95\%: 1.03 to 1.60) compared to placebo. (Rossouw et al., 2002; Hulley et al., 1998; Lufkin et al., 1992) 
The combined HRT group of the WHI study, showed an increase in the risk of invasive breast cancer. (Rossouw et al., 2002) This increase took place after the fourth year of treatment ( $R R=1.26$; $C I 95 \%$ : 1.0 to 1.59), with a tendency to increase according to the duration of the treatment (38 cases compared with 30 for 10,000 women/year). The patients in the treatment group were diagnosed in more advanced stages. No significant differences were found for the in situ carcinoma. (Chlebowski et al., 2003) Moreover, other studies have demonstrated that both the sequential and the continuous administration of the progestagens, collaborate to increase breast cancer. (Li et al., 2003)

\subsubsection{Endometrial cancer}

The administration of isolated estrogen increases the risk of developing endometrial hyperplasia and cancer. (Lethaby et al., 2004; Nelson, 2004) A meta-analysis including 29 observational studies showed a significant increase in the endometrial cancer risk with or without combined estrogens ( $R R=2.3$; $C I$ 95\%: 2.1 to 2.5). (Grady et al., 1995) This risk is proportional to the duration of the treatment and remains elevated for up to 5 years or more after stopping treatment. In addition, an increase in endometrial cancer mortality was observed, but it was a non-significant increase ( $R R=2.7$; CI $95 \%$ : 0.9 to 8.0). The combined HRT group of the WHI study and its continuation for secondary prevention (HERS II) showed a relative risk of endometrial cancer of 1.58 without reaching statistical significance (IC 95\%: 0.77 to 3.24). (Menopause and post menopause workgroup, 2004)

\subsubsection{Ovarian cancer}

In a systematic review of several case-control studies no association could be found between HRT and ovarian cancer. (Coughlin et al., 2000) In contrast, more recent systematic reviews of observational studies confirm the increase in the risk of ovarian cancer in women receiving treatment, especially long-term treatment (more than 10 years). (Garg et al., 1998; Negri et al., 1999) Two cohort studies of postmenopausal women treated for more than 10 years confirm this risk increase ( $R R=2.2$; $C I$ 95\%: 1.53 to 3.17 ), as well as the mortality risk (RR=1.59; CI 95\%: 1.13 to 2.25). (Lacey et al., 2002; Rodriguez et al., 2001) The combined HRT group of the WHI study also showed a non-significant increase in the risk of ovarian cancer ( $R R=1.58$; CI $95 \%$ : 0.77 to 3.24). (Anderson et al., 2003)

In summary, HRT is effective for the treatment of postmenopausal osteoporosis and the reduction of fracture risk. In spite of this, it is not advisable to use HRT (combined estrogen and progestagens) for more than 5 years due to the potential risks associated with the treatment of an equivalent dose of 50 picograms of estradiol per day. When HRT is indicated, it has to be prescribed at low doses (equivalent to estrogen transdermal patches of $25 \mathrm{mcg}$ ) and only if strictly necessary, higher doses. Estrogens and progestagens are recommended only in women with intact uteri. The progestagen dose must be calculated according to the estrogen dose. In those cases where a hysterectomy was performed due to endometrial cancer, HRT must not combine estrogen and progestagens. Continuous combined HRT must not be started until after one year of menopause.

\subsection{Selective estrogen receptor modulators (SERMs)}

So far two estrogen receptors have been described, alpha (ER $\alpha)$ and beta (ER $\beta)$, which are at different levels and locations in different body tissues. The ER $\beta$ are mainly in the developing spongy bone, while ER $\alpha$ are concentrated more on the cortical bone. In addition, these receptors have differences in their structure and function, which would explain other effects of estrogen deficiency as vasomotor symptoms or alterations in the lipid profile. 
The selective estrogen receptor modulators are drugs with selective effects on the estrogen receptor. They can act as estrogen receptor agonists in some tissues while acting as estrogen receptor antagonists in others. SERMs embrace diverse molecules that lack the steroid structure of estrogens, but own a tertiary structure that allows them to bind to ER $\alpha$ and/or ER $\beta$ with different potency. In contrast to estrogens and estrogen receptor agonists, these are partial agonists/antagonists. Due to their selective estrogen-agonist properties on different tissues, SERMs may be indicated for the prevention or treatment of diseases caused by estrogen deficiency, like osteoporosis, without some of the adverse effects of estrogens. In addition, due to their selective properties in the breast (estrogen receptor antagonists), SERMs can be also utilized to prevent or treat breast cancer, where estrogen-agonistic activity is not wanted.

\subsubsection{Differences between SERMs}

Currently there are two types of SERMs that are differentiated by their chemical structure: triphenylethylene derivatives, such as tamoxifen and toremifene, and a benzothiophene derivative, raloxifene. The first two are used for the treatment of breast cancer while raloxifene is indicated for the prevention and treatment of osteoporosis. All have been associated with an increased incidence of pulmonary thromboembolism and with the onset of hot flushes but they have a beneficial effect on the lipid profile.

Tamoxifen is not indicated for the treatment of osteoporosis due to increased incidence of endometrial cancer associated with prolonged treatment and the weak effect of this drug on bone that is not maintained over time. The results of the studies that evaluated the effect of tamoxifen on fracture risk were contradictory.

The SERMs differ significantly in terms of tissue specificity. Bazedoxifene seems to have less effect on the uterus than estradiol and raloxifene in animal experiments due to lower estrogen receptor alpha agonistic effects. Tamoxifen and toremifene are used to treat breast cancer. Raloxifene is indicated for the treatment and prevention of osteoporosis and for the prevention of breast cancer. Besides the SERMs described in this review, other new SERMS have had clinical trials suspended prematurely: levormeloxifene, for causing urinary incontinence and uterine prolapse, arzoxifene for lacking effectiveness, and idoxifene, for resulting in increased endometrial thickness on ultrasonography but without significant histological abnormality.

\subsection{Raloxifene}

Raloxifene has estrogenic activity in bone and other systems but not in reproductive tissue. In ovariectomized animals, raloxifene preserves bone density, lowers serum total cholesterol, and inhibits aortic cholesterol accumulation, without causing endometrial hyperplasia. The mechanism of selectivity of raloxifene is not fully understood. There are studies that suggest that raloxifene has different effects than estradiol at the estrogen receptor. It also seems to have a different modulation in DNA response.

Several studies have demonstrated the effectiveness of raloxifene in the preservation of bone in early postmenopause. In a meta-analysis of seven trials (four treatment and three prevention trials) examining the effects of raloxifene versus placebo on bone mineral density, raloxifene increased bone mineral density of the lumbar spine after two years of treatment. (Cranney et al., 2002) A study with 601 women, five years after menopause, that received a daily treatment with 30,60 or $150 \mathrm{mg}$ of raloxifene for two years, showed an 
increase in bone mineral density in spine and hip, while the placebo was associated with reduced bone mineral density at the same sites. (Delmas et al., 1997) Compared to placebo, the average change in BMD with $60 \mathrm{mg}$ of raloxifene was $2.4 \%$ at the spine and $2.4 \%$ at the total hip ( $p<0.001$ vs placebo). However, in two placebo-controlled trials with 1455 -year postmenopausal women 60 years or younger, treatment with raloxifene for three years showed a minor effect on spine and hip BMD. (Johnston et al., 2000) The change in BMD of the spine at three years was $-1.32 \%$ with placebo, $0.71 \%$ with $30 \mathrm{mg}$ of raloxifene, $1.28 \%$ with $60 \mathrm{mg}$ raloxifene and $1.2 \%$ with $150 \mathrm{mg}$ of raloxifene. Similar changes in hip BMD were observed in the respective treatment groups. In another analysis two studies involving 328 women with a mean age of 55 years and five years after menopause, treatment for five years with $60 \mathrm{mg}$ of raloxifene was associated with preservation of BMD and a reduced risk of osteoporosis compared with the placebo group. The treatment with raloxifene compared to placebo showed an average increase in BMD of $2.8 \%$ at the lumbar spine and $2.6 \%$ at the hip (in both $\mathrm{p}<0.001$ ). (Jolly et al., 2003)

Raloxifene has shown to be effective in reducing the risk of invasive breast cancer in older women. Postmenopausal women with low bone mass and osteoporosis were studied in a trial named Multiple Outcomes of Raloxifene Evaluation (MORE, n=7,705) and its complementary study, called the Continuing Outcomes Relevant to Evista (CORE, n=4,011). (Burshell et al., 2008) In this study, women had an average age of 65 years (group with low bone mass) and 68 years (group with osteoporosis) and were followed for eight years. Regarding fractures, raloxifene reduced the risk of vertebral fracture; however, it did not show a reduction in non-vertebral fractures. Moreover, in a meta-analysis of RCTs comparing raloxifene to placebo, raloxifene consistently reduced the risk of vertebral fractures in postmenopausal women (OR=0.6; CI 95\%: 0.5-0.7).

In the MORE trial, a subset of 6,828 of the women had lumbar spine $x$-rays at baseline and after 36 months of treatment. Among the women receiving $60 \mathrm{mg}$ and $120 \mathrm{mg}$ raloxifene new vertebral fractures were observed in $6.6 \%$ and $5.4 \%$, respectively, compared with $10.1 \%$ in the placebo group. The risk of non-vertebral fracture was similar in the three groups. After four years of raloxifene treatment ( $60 \mathrm{mg}$ per day), the cumulative relative risk of one or more vertebral fractures was 0.64 (IC 95\%: 0.53 - 0.76), compared with placebo.

Compared with placebo, treatment with $60 \mathrm{mg}$ of raloxifene was associated with a reduction of 65 to $78 \%$ in the incidence of invasive breast cancer and breast invasive cancer with positive estrogen receptor (both $\mathrm{p}<0.05$ ). Therefore, the FDA approved raloxifene to reduce the risk of invasive breast cancer in postmenopausal women at high risk. (Barrett-Connor et al., 2006)

\subsubsection{Combination therapy}

The combination of alendronate and raloxifene resulted in a greater increase in BMD when compared with either drug alone. (Johnell et al., 2002) However, the benefit of combined versus monotherapy for fracture reduction is unknown and there are additional costs and side effects of taking two agents. As explained previously, some trials have reported that raloxifene (either taken concurrently or prior to $\mathrm{PTH}$ ) does not suppress the BMD response to $\mathrm{PTH}$ as much as alendronate.

\subsubsection{Adverse events}

Several adverse events are associated with raloxifene. In the MORE and CORE studies an association between raloxifene and a 1.7 times increased risk of thromboembolism (TE), 
compared with placebo, was observed (95\% CI: 0.93-3.14; risk difference total of 0.9/1,000 women-years). (Martino et al., 2005) In a meta-analysis of nine studies, therapy with raloxifene was associated with an increase in the risk of deep venous thrombosis and pulmonary embolism (OR=1.5; CI 95\%: 1.1-2.1 and $\mathrm{OR}=1.9 ; 95 \% \mathrm{CI}$ : 1.0-3.5, respectively). (Adomaityte et al., 2008)

In the RUTH study (Raloxifene Use for The Heart), which included 10,101 postmenopausal women with coronary heart disease and an average age of 68 years, there was an association between Raloxifene and an increased risk of fatal stroke (HR=1.49; 95\% CI: 1.00-2.24, an increase in the absolute risk of $0.7 / 1,000$ women-years) and thromboembolism (HR=1.44; 95\% CI: 1.06-1.95, an increase absolute risk of 1.2/1,000 women-years) compared with placebo. There was no increased risk of myocardial infarction or other coronary events in the RUTH study. However, as observed with thromboembolism and pulmonary embolism, the results of a recent analysis in a subgroup of the study showed an effect of age on incidence of coronary events, among women 60 years old or younger, the incidence of coronary events was significantly lower with raloxifene (50 cases), compared with the placebo group ( 84 cases; $\mathrm{HR}=0.59 ; 95 \% \mathrm{CI}$ : 0.41 to $0.83, \mathrm{p}=0.003$ ). Raloxifene was also associated with an increase in hot flushes, particularly in women with new onset menopause. In MORE and CORE trials, $12.6 \%$ of women receiving raloxifene had hot flushes, compared with $6.9 \%$ in the placebo group ( $\mathrm{p}<0.0001)$. (Collins et al., 2009)

In conclusion, raloxifene offers an alternative in the treatment of osteoporosis in selected patients. Its profile regarding heart disease and breast cancer is good but it should be carefully considered especially due to the high risk of venous thrombosis.

\subsection{Bazedoxifene}

Bazedoxifene is a novel, non-steroidal, indole based SERM that was developed using a rigorous preclinical screening process designed to select therapies with favorable effects on bone and lipid profiles while reducing the stimulation of uterus or breast tissue. (Komm et al. 2005; Komm \& Lyttle, 2001) It is a third-generation SERM after the first generation tamoxifene, and the second-generation raloxifene. (Bazedoxifene: bazedoxifene acetate, 2008) Significant differences have been shown between the generations in terms of effects especially on the uterus and the breast tissue. (Vogel et al., 2006) It was developed using raloxifene as a template with the benzothiophene core substituted by an indole ring. (Gruber \& Gruber 2004)

\subsubsection{Pharmacokinetics and pharmacodynamics}

Bazedoxifene is quickly absorbed with a t-max of approximately 2 hours and displays a linear increase in plasma concentrations after single doses from $0.5 \mathrm{mg}$ up to $120 \mathrm{mg}$. (Chandrasekaran et al., 2009) It is highly bound (95.8\% to $99.3 \%)$ to plasma proteins in vitro and it is extensively metabolized in women. Glucuronidation is the most important metabolic pathway. Slight or no cytochrome P450-mediated metabolism is apparent. Bazedoxifene-5-glucuronide is the major circulating metabolite and the concentrations of this glucuronide are approximately 10-fold higher than those of non-metabolized active substance in plasma. Bazedoxifene is excreted principally by feces and has a half-life of approximately 30 hours. Steady-state concentrations are achieved by the second week of once-daily administration. (Biskobing 2007; Shen et al., 2010) To study the bioavailability of bazedoxifene two oral formulations, a $10 \mathrm{mg}$ tablet and two $5 \mathrm{mg}$ capsules, and a $3 \mathrm{mg}$ IV formulation were given to 18 postmenopausal women in a 3-way crossover design. Blood 
was collected for 168 hours after each dose. The bioavailabilty of bazedoxifene was $6.2 \%$ for both oral formulations. (Patat et al., 2003) Finally, a study evaluated the longer-term pharmacokinetics of multiple doses of bazedoxifene. In a randomized, crossover study 23 postmenopausal women were given multiple doses of bazedoxifene $(5,20,40 \mathrm{mg})$ for 14 days. Maximum concentration was achieved in 1-2 hours and $t^{1 / 2}$ was approximately 28 hours. Protein binding was greater than $99 \%$. Steady state concentrations were achieved by day 7. (Ermer et al., 2003)

\subsubsection{Bazedoxifene in humans}

Human studies with bazedoxifene have demonstrated a decreased thickness of the endometrium at doses of 30 to $40 \mathrm{mg}$ / day compared to placebo or conjugated estrogen plus medroxyprogesterone (mean \pm standard error of the mean increase after 168 days: $0.04 \pm$ $0.12 \mathrm{~mm}$ for $30 \mathrm{mg}, 0.12 \pm 0.11 \mathrm{~mm}$ for $40 \mathrm{mg}, 0.58 \pm 0.21 \mathrm{~mm}$ for placebo, and $1.60 \pm 0.23$ $\mathrm{mm}$ for conjugated estrogen plus medroxyprogesterone acetate). (Ronkin et al., 2005) In a phase 2 study of healthy postmenopausal women, daily oral doses of bazedoxifene 2.5, 5.0, $10,20,30$, or $40 \mathrm{mg}$ were generally well tolerated and did not stimulate the endometrium. Furthermore, bazedoxifene 30 and $40 \mathrm{mg}$ caused significantly smaller increases in endometrial thickness and significantly reduced the incidence of uterine bleeding compared with placebo. In a 2-year phase 3 study of postmenopausal women at risk of osteoporosis, bazedoxifene 10, 20, and $40 \mathrm{mg}$ showed to prevent bone loss and reduce bone turnover and was associated with a favorable endometrial, ovarian, and breast safety profile. (Ronkin et al., 2005; Pinkerton et al., 2009; Miller et al., 2008; Archer et al., 2009)

A phase III, multicenter, double-blind, randomized, placebo-controlled study was designed exclusively to evaluate the efficacy of bazedoxifene for the prevention of fractures (Silverman et al., 2008). The study comprised 7,492 healthy postmenopausal women with osteoporosis with or without prevalent vertebral fractures. Participants were randomized to 20 or $40 \mathrm{mg}$ per day of bazedoxifene, $60 \mathrm{mg}$ of raloxifene, or placebo plus $1200 \mathrm{mg}$ of calcium and $400 \mathrm{IU}$ of vitamin $\mathrm{D}$. The primary endpoint was the incidence of new vertebral fractures after 36 months. Secondary outcomes included, clinical vertebral fractures, worsening of vertebral fractures, non-vertebral fractures, breast cancer incidence, and changes in height. Both bazedoxifene 20 and $40 \mathrm{mg}$ prevented the incidence of vertebral fractures with a similar efficacy as raloxifene when compared to placebo. The 3-year incidence of new vertebral fractures were $2.3 \%, 2.5 \%$, $2.3 \%$, and $4.1 \%$ in the bazedoxifene $20 \mathrm{mg}$, bazedoxifene $40 \mathrm{mg}$, raloxifene $60 \mathrm{mg}$, and placebo groups, respectively, with a significant reduction in relative risk for new vertebral fracture of $42 \%, 37 \%$, and $42 \%$, respectively, versus placebo. There was in general no effect on nonvertebral fractures, with incidence rates of $5.7 \%$ and $5.6 \%$ for the bazedoxifene 20 and $40 \mathrm{mg}$ groups, respectively, compared with $5.9 \%$ for the raloxifene treatment group and $6.3 \%$ for the placebo group. Though, in a post-hoc analysis of women with higher risk for fractures (low femoral neck T-score and multiple vertebral fractures, $n=1,772)$ bazedoxifene $20 \mathrm{mg}$ demonstrated a $50 \%$ and $44 \%$ reduction in non-vertebral fracture risk compared with placebo $(\mathrm{HR}=0.50 ; 95 \% \mathrm{CI}: 0.28-0.90 ; \mathrm{p}=0.02)$ or raloxifene $60 \mathrm{mg}(\mathrm{HR}=0.56$; 95\% CI: 0.31-1.01; $\mathrm{p}=0.05)$, respectively. (Silverman et al., 2008)

\subsubsection{Bazedoxifene and conjugated estrogen combination therapy}

The rationale for selecting bazedoxifene as the SERM in this combination is that it may counterbalance estrogen stimulation of endometrial and breast tissue, without the 
requirement for using a progestin in women with an intact uterus or menopausal vasomotor symptoms, while preserving or increasing BMD. (Gruber \& Gruber, 2004; Lewiecki, 2007a) The combination of a SERM with conjugated estrogen has directed to a new class of menopausal therapy called "tissue selective estrogen complex (TSEC)". (Stovall \& Pinkerton, 2008)

Preclinical studies have shown that bazedoxifene antagonizes estrogen-induced uterine and mammary gland stimulation more effectively than other SERMs like raloxifene and lasofoxifene. (Peano et al., 2009; Kharode et al., 2008) A randomized, double-blind, placebocontrolled Phase III trial in 3,397 postmenopausal women examined the effect of bazedoxifene 10, 20, or $40 \mathrm{mg}$ combined with conjugated estrogens $0.625 \mathrm{mg}$ or $0.45 \mathrm{mg}$ on bone and endometrium. In this trial, the bazedoxifene plus conjugated estrogen combination therapy showed a statistically significant increase in BMD and a decrease in bone biochemical turnover markers compared with placebo. In addition to the positive effects on bone, bazedoxifene plus conjugated estrogen therapy significantly reduced the incidence and severity of hot flushes and improved vulvo-vaginal atrophy compared with placebo, with a good safety and tolerability profile. (Archer et al., 2009; Lobo et al., 2009; Pickar et al., 2009; Lindsay, 2011)

\subsubsection{Safety}

Miller et al., showed that deep venous thromboembolism was rare with bazedoxifene $(0 \%$ to $0.6 \%$ with various doses after 2 years) and similar to placebo $(0.3 \%)$. Leg cramps were similar to raloxifene and placebo. Hot flushes incidence and severity were comparable to raloxifene, but a little higher than with placebo. (Miller et al., 2008) In the study by Silverman et al, leg cramps ( $10.9 \%$ to $11.7 \%$ with various doses after 3 years) and deep venous thromboembolism ( $0.4 \%$ to $0.5 \%$ with various doses after 3 years) were significantly more common with bazedoxifene than with placebo ( 8.2 for leg cramps and $0.2 \%$ for deep venous thromboembolism), while breast cyst/fibrocystic breast disease was significantly less frequent. No difference between bazedoxifene and placebo were observed for myocardial infarction, strokes (ischemic or hemorraghic), or retinal vein thrombosis. (Miller et al., 2008; Silverman et al., 2008; Mitwally, 2008)

In conclusion, bazedoxifene seems to have enhanced selectivity compared to other SERMs. Preclinical and clinical studies suggest slight stimulatory effects on uterine tissue and the ability to antagonize estrogen uterine effects. In addition, it does not appear to increase hot flushes. In vitro studies suggest inhibitory effects, at the breast although no long-term clinical data is available on effects on breast cancer rates. The effect of bazedoxifene on the skeleton is similar to raloxifene, and bazedoxifene may be used just as raloxifene. The value of bazedoxifene may reside in a different risk profile than raloxifene, especially in terms of uterine safety, and bazedoxifene may consequently offer an alternative for prevention and treatment of osteoporosis.

\subsection{Lasofoxifene}

Lasofoxifene is potent third generation SERM, discovered through a synthetic program intended to isolate innovative molecules with good oral bioavailability and higher potency in vivo. It is a naphthalene derivative, structurally different from the first- and secondgeneration SERMs raloxifene, tamoxifen and clomiphene or idoxifene. Lasofoxifene has potent estrogenic and anti-estrogenic activity in vitro and in vivo, targeting any tissues that 
have estrogens receptors, such as bone, uterus, breast, blood vessels, and liver. Competitive binding experiments demonstrate high affinity of the compound for both ERa and ER $\beta$. Like other SERMs, lasofoxifene specifically binds to human ERa with high affinity and with a half-inhibitory concentration (IC50) which is similar to that seen with estradiol and consequently at least 10 -fold higher than those reported for raloxifene, tamoxifen and droloxifene. Lasofoxifene also shows a high affinity for the human ER $\beta$ similar to the one of estradiol. (Gennari et al., 2010; Peterson et al., 2011; Swan et al., 2010)

Lasofoxifene has been investigated in postmenopausal women for the prevention and treatment of osteoporosis as well as for the treatment of vaginal atrophy. In a 2-year, randomized, double-blind study comprising 410 postmenopausal women, the mean change in lumbar spine BMD compared to placebo was significantly greater $(\mathrm{p}<0.05)$ with lasofoxifene 0.25 and $1.0 \mathrm{mg} /$ day $(3.6 \%$ and $3.9 \%$, respectively) compared with raloxifene $60 \mathrm{mg}(1.7 \%)$, although the results were comparable in total hip BMD. Lasofoxifene, as well as raloxifene, significantly reduced bone turnover markers and low-density lipoprotein cholesterol compared with placebo. Results have shown that treatment with lasofoxifene improves signs and symptoms of vaginal atrophy, as well as dyspareunia. (McClung et al., 2006a)

Safety and tolerability of lasofoxifene is comparable to that of raloxifene, although discontinuation rates due to adverse events are more common with lasofoxifene. In spite of these findings, evidence proves that lasofoxifene treatment may cause increased endometrial thickness compared with placebo, even though there has been no evidence of an increased risk of endometrial hyperplasia or cancer. Lasofoxifene did not get FDA approval for the treatment of vaginal atrophy. (Kulak Junior et al., 2010)

The PEARL trial, a 3-year pivotal fracture trial demonstrated that lasofoxifene increased lumbar spine and femoral neck BMD by roughly 3\%. Moreover vertebral fractures were reduced by $42 \%$, and non-vertebral fractures by $27 \%$, with reduction in markers of bone turnover. Even though, lasofoxifene did not prevent hip fractures. (Clarke \& Khosla 2009)

\subsection{Bisphosphonates}

\subsubsection{Overview and mechanism of action}

Bisphosphonates belong to a class of antiresorptive drugs, whose antifracture action is well established in randomized controlled trials. It is important to remember that a direct comparison between them has not been made, which avoids establishing a clear superiority order. There were attempts to compare them through the respective trials and the respective risk reductions, but this approach has limitations that can only be overcome with direct and randomized trials of the different drugs.

Bisphosphonates reduce the risk of fracture due to its inhibitory action of osteoclasts, which allows the osteoblasts to synthesize bone in the resorption spaces and some bone lacunae. This leads to an increase in bone mass. But, in addition, the bisphosphonates improve bone quality, by preserving the bone architecture, as shown in trials, in which the biopsies of the treated patients and controls have been studied. When the treatment with bisphosphonates is indicated, it is essential to administer calcium and vitamin D to assure its maximum antifracture efficacy. (Olmos-Martinez \& Gonzalez-Macias 2008)

Farnesyl pyrophosphate synthase (FPPS) is an essential regulatory enzyme in the mevalonate pathway. This pathway is important for the production of dimethylallyl pyrophosphate (DMAPP) and isopentenyl pyrophosphate (IPP), which serve as the foundation for the biosynthesis of molecules used in processes as diverse as terpenoid 
synthesis, protein prenylation, cell membrane maintenance, hormones, protein anchoring, and N-glycosylation. It is also very important in steroid biosynthesis. Blocking this pathway has a variety of clinical uses, i.e. with statins for the inhibition of hydroxymethylglutaryl$\mathrm{CoA}$ reductase and thus reducing cholesterol biosynthesis, and nitrogenated bisphosphonates used for osteoporosis treatment. (Kavanagh et al., 2006)

Bisphosphonates are pyrophosphate analogs in which the central oxygen has been substituted by a carbon atom and two side chains (R1 and R2). Their intestinal absorption is very low but the affinity for bone is extreme, and once there, they act as very potent antiresorptives. Two phosphate groups are essential so they can bind to bone and for the antiresorptive effect. The long side-chain (R2) determines the chemical properties, the mode of action and the strength of bisphosphonate drugs. The short side-chain (R1), principally influences pharmacokinetics and chemical properties. (Olmos-Martinez \& Gonzalez-Macias 2008; Kavanagh et al., 2006)

While some of the first generation bisphosphonates such as etidronate and clodronate act by reversing pyrophosphorylytic reactions catalyzed by aminoacyl-tRNA synthetases, thus producing the corresponding pyrophosphonate analogs of adenosine tri phosphate and osteoclast apoptosis, the action of the nitrogenated bisphosphonates involves a different mechanism, inhibiting the FPPS activity in the mevalonate pathway. Their superior potency results from two main properties: the affinity for bone mineral and the ability to inhibit osteoclast function. (Olmos-Martinez \& Gonzalez-Macias 2008)

The difference in potency of the different nitrogenated bisphosphonates depends on their affinity for bone and their capacity of inhibiting FPPS. Their affinity for bone tissue provide bisphosphonates with the capacity of remaining embedded in bone matrix for a long time, thus providing the possibility of weekly, monthly or even yearly regimens. As mentioned earlier, bisphosphonates are poorly absorbed by the intestine (between 1\% and 3\%) and consequently bioavailability can vary considerably. The new third generation bisphosphonates are administered intravenously, avoiding this difficulty and accordingly increasing the effect of these drugs. (Olmos-Martinez \& Gonzalez-Macias 2008)

\subsection{Etidronate}

This bisphosphonate was the first one introduced into osteoporosis treatment. At the present time, it is practically not used anymore. Its biggest advantage is probably its price. It increases bone mass in the spine and femur. It reduces the incidence of vertebral fractures; however it has not proven to diminish femoral fractures. Its administration is oral and cyclic, a dose of $400 \mathrm{mg}$, once a day, during 2 weeks and repeated every 90 days. During the intervals calcium is administrated. There is only one study where its intravenous administration was compared with clodronate and placebo for a short period, and it reduced bone mass loss in the spine.

\subsection{Clodronate}

It has been used for postmenopausal osteoporosis treatment in oral and intravenous regimes. The studies show that it prevents bone loss in vertebral spine when comparing with controls, and it has similar effects to estrogens at 2 years. In a 6-year trial, it was observed that it not only increased bone mass, but it also reduced vertebral fractures. McCloskey et al. conducted a 3-year, double blind, placebo controlled trial to study the effect of oral clodronate ( $800 \mathrm{mg}$ daily) in fracture prevention. In this trial clodronate was 
associated with a significant increase in the mean lumbar spine and hip BMD. Moreover, it significantly reduced vertebral fracture risk (relative risk, $0.54 ; 95 \% \mathrm{CI}, 0.37-0.80 ; \mathrm{p}<0.0001$ ). Rovetta et al. have published a study that shows that treating osteoporotic vertebral fractures with $300 \mathrm{mg}$ of intravenous clodronate may have better results than paracetamol in reducing pain. In spite of these results, since the discovery of the potent nitrogen bisphosphonates, the first generation bisphosphonates have been relegated to the last line of treatment. (McCloskey et al., 2004)

\subsection{Alendronate (Alendronic acid)}

Alendronate is one of the bisphosphonates most widely used. It increases vertebral bone mass around $6-8 \%$ and 3-6\% at the hip in postmenopausal osteoporotic women treated for 3 years. It shows a decrease of vertebral and non-vertebral fractures of about $50 \%$ in this period of time. Ninety five percent of postmenopausal women respond maintaining or increasing bone mass. Alendronate has shown to be able to prevent loss of bone mass of postmenopausal young women with osteopenia and in fragile old women living in retirement homes. In male osteoporosis, it has showed increases of $5 \%$ in bone mass at 2 years of treatment. There is reliable security data of the drug at 10 years. Alendronate is approved by the Food and Drug Administration (FDA) of the United States for the treatment of osteoporosis in men and glucocorticoid-induced osteoporosis.

It is administered orally, in weekly doses of $70 \mathrm{mg}$, fasting with $200 \mathrm{ml}$ of water. The intake of food or drinks has to be avoided in the next 30 minutes and orthostatism has to be kept for this time. There is a preparation of alendronate, which has been available since 2007, that combines the drug with $2,800 \mathrm{U}$ or 5,600 IU of vitamin D. Even though it is commercialized with another name, it is administered in the same way as alendronate alone and it is indicated in patients that need a supplement of vitamin $\mathrm{D}$, but have an adequate intake of calcium.

The pivotal trial of alendronate, the FIT (Fracture Intervention Trial), showed that the risk of any clinical fracture was lower in the alendronate than in the placebo group (139 $(13.6 \%)$ vs $183(18.2 \%)$; relative hazard $=0.72(0.58-0.90))$. The relative hazards for hip fracture and wrist fracture for alendronate versus placebo were 0.49 (0.23-0.99) and 0.52 (0.31-0.87). (Black et al. 1996) Ensrud et al. published the analysis of a sub group of patients of the FIT. These patients were patients at high risk of fracture. Their results show a $47 \%$ significant reduction in risk of new vertebral fractures in the alendronate group compared with the placebo group. The reduction in risk of new vertebral fracture was consistent across fracture risk categories including age $(R R=0.49$ in women $<75$ years compared with 0.62 in those $\geq 75$ years), BMD $(\mathrm{RR}=0.54$ in women with a femoral neck $\mathrm{BMD}<0.59 \mathrm{~g} / \mathrm{cm} 2$ [median] compared with 0.53 in those with a $B M D \geq 0.59 \mathrm{~g} / \mathrm{cm} 2)$, and number of preexisting vertebral fractures $(R R=0.58$ in women with 1 vertebral fracture compared with 0.52 in those with $\geq 2$ ). The overall significant $28 \%$ reduction in risk of incident clinical fractures in the alendronate group compared with the placebo group was also observed within these subgroups. (Ensrud et al., 1997) Several other publications have derived from the FIT population, studying multiple symptomatic fractures, bone mineral density, biochemical markers of formation and resorption, fracture prevention in osteopenic women, effect of alendronate continuation versus discontinuation, and effect in those women who lost bone during treatment. (Levis et al., 2002; Bauer et al., 2004; Chapurlat et al., 2005; Quandt et al., 2005)

In conclusion, alendronate is a well-tolerated, safe and effective drug for the treatment of postmenopausal osteoporosis, osteoporosis in men and glucocorticoid induced osteoporosis. 


\subsection{Risedronate}

This drug has showed to increase bone mass in spine and hip and to significantly reduce the risk of fracture in postmenopausal women. Treatment of postmenopausal women with osteoporosis with risedronate during three years has shown to reduce vertebral fractures in approximately $50 \%$ and non-vertebral fractures in $39 \%$. At the hip, the fracture reduction is between 40 and $60 \%$. At 5 years, the results are similar. The drug has shown anti fracture efficacy after 6 months of administration. In other studies it has been confirmed that the efficacy still remains after 7 years of treatment with a good security profile. Risedronate has shown to be efficient in the prevention of spinal and femoral bone mass loss in patients with osteopenia. The first available preparation was $5 \mathrm{mg}$ that was administered daily. A couple of years later a preparation of $35 \mathrm{mg}$ became available and had to be taken weekly. Finally, about two years ago, a preparation of $150 \mathrm{mg}$ came out to be taken every month. In Europe, this preparation was split into two $75 \mathrm{mg}$ capsules that have to be taken on consecutive days once a month. Every dosage preparation of risedronate has to be taken following the instructions of oral bisphosphonate administration mentioned earlier.

In one of the main trials of risedronate, McClung et al, studied 5445 women 70 to 79 years old diagnosed with osteoporosis ( $\mathrm{T}$ score at the femoral neck more than -4 SD below the mean or lower than -3 plus a non-skeletal risk factor for hip fracture, such as poor gait or a tendency to fall) and 3886 women at least 80 years old with at least one non-skeletal risk factor for hip fracture or low bone mineral density at the femoral neck (T score, lower than 4 or lower than -3 plus a hip-axis length of $11.1 \mathrm{~cm}$ or greater). The patients were randomly assigned to receive treatment with oral risedronate $(2.5$ or $5.0 \mathrm{mg}$ daily) or placebo for three years. The primary end point was the incidence of hip fracture. The results showed that the incidence of hip fracture among the patients assigned to risedronate was $2.8 \%$, as compared with $3.9 \%$ among those assigned to placebo (relative risk, $0.7 ; 95 \% \mathrm{CI}, 0.6$ to $0.9 ; \mathrm{p}=0.02$ ). In the group of women with osteoporosis (those 70 to 79 years old), the incidence of hip fracture among those assigned to risedronate was $1.9 \%$, as compared with $3.2 \%$ among those assigned to placebo (relative risk, $0.6 ; 95 \% \mathrm{CI}, 0.4$ to $0.9 ; \mathrm{p}=0.009$ ). In the group of women selected primarily on the basis of non-skeletal risk factors (those at least 80 years of age), the incidence of hip fracture was $4.2 \%$ among those assigned to risedronate and $5.1 \%$ among those assigned to placebo ( $\mathrm{p}=0.35)$. (McClung et al., 2001)

To evaluate vertebral fracture risk reduction, Reginster et al, completed a randomized, double-blind, placebo-controlled study to determine the efficacy and safety of risedronate in the prevention of vertebral fractures in postmenopausal women with established osteoporosis. The study was conducted at 80 study centers in Europe and Australia. A total of 1226 postmenopausal women with two or more prevalent vertebral fractures received risedronate $2.5 \mathrm{mg}$ or $5 \mathrm{mg}$ daily or placebo. The study lasted 3 years; however, the $2.5 \mathrm{mg}$ group was discontinued by protocol amendment after 2 years. Lateral spinal radiographs were taken annually for evaluation of vertebral fractures, and BMD was measured every 6 months. Risedronate $5 \mathrm{mg}$ reduced the risk of new vertebral fractures by $49 \%$ over 3 years compared with control $(\mathrm{p}<0.001)$. A significant reduction of $61 \%$ was observed within the first year $(p=0.001)$. The fracture reduction was similar in both groups at 2 years. The nonvertebral fracture risk was reduced by $33 \%$ compared with control over 3 years $(p=0.06)$. Risedronate significantly increased BMD at the spine and hip within 6 months. In conclusion, risedronate $5 \mathrm{mg}$ was an effective and well-tolerated therapy for severe postmenopausal osteoporosis, reducing the incidence of vertebral fractures and improving bone density in women with established disease. (Reginster et al., 2000) 


\subsection{Ibandronate}

Its absorption is similar to the one of the rest of the oral bisphosphonates since only $0,6 \%$ of the administrated dose is absorbed. The administration instructions are also the same as the other oral bisphosphonates, because if it is administered concomitantly with food, the plasmatic concentrations can decrease up to $90 \%$. In studies at 3 years, it has shown to reduce vertebral fractures $(52 \%)$ and increase vertebral BMD (6.5\%) without presenting significant adverse effects or changes in bone histology. It also avoids bone loss in postmenopausal women with osteopenia and it has proven to be very efficient in preventing bone loss in Glucocorticoid-induced osteoporosis. In women with severe osteoporosis ( $\mathrm{T}$ score <-3), it reduces non-vertebral fractures up to $69 \%$. (Chesnut, 2006)

It is administered orally in a monthly dose of $150 \mathrm{mg}$ and also intravenously every three months in a dose of $2 \mathrm{mg}$. Randomized clinical trials like MOPS (Monthly Oral Pilot Study) or MOBILE (Monthly Oral Ibandronate in Ladies) have shown that the ibandronate monthly dose is as effective and secure as the daily dose. In the general population of the pivotal trial (BONE, Oral Ibandronate Osteoporosis Vertebral Fracture Trial in North America and Europe), the frequency of adverse events of the gastrointestinal tract in the daily dose and the intermittent dose was comparable to the one of placebo. Dyspepsia was the only adverse event with a slight superior frequency in patients in active treatment with ibandronate. (Delmas et al., 2004)

In different chronic therapeutical areas it has been shown that, for oral bisphosphonates, the treatment compliance is poor and, besides, it decreases with time. This has a big impact on the drug's effectiveness, since the early interruption and bad compliance decrease significantly the benefit that these drugs could have. In order to show the importance of the problem, a sub study, with data of the IMPACT study was made. More than 2,300 postmenopausal women were treated for osteoporosis with risedronate. The analysis showed, that, in contrast to the women who did not accomplish the treatment, most of the women, who complied with the treatment, had decreases in the bone resorption markers. In other analysis, that included patients with osteoporosis and osteopenia from a Canadian data base, it was shown that patients with a treatment compliance higher than above $80 \%$ had increases in bone mineral density and these were significantly higher than the ones from patients who did not accomplish this requirement. The strict administration requirements that are needed caused some patients to interrupt the treatment with bisphosphonates and it was a reason for some not to start it. In a 6-month study with alendronate, $14.3 \%$ of the patients mentioned discomfort as the reason for interrupting the treatment. In prospective trials of crossover treatment it has been shown that the least frequent administration of bisphosphonates increases the treatment compliance. That is why the use of ibandronate with monthly intake could be of benefit. (Delmas et al., 2007) On the other hand, ibandronate has not shown, in randomized controlled trials, reductions in the incidence of non-vertebral or hip fractures.

\subsection{Zoledronate (Zoledronic acid)}

Zoledronic acid is a third generation bisphosphonate. Its complete chemical name is 1hydroxi-2-(1H-imidazol-1-y-1)ethylidene) bisphosphonic acid. The experience with this drug is more extensive in the oncology area. Besides oncology, zoledronic acid has other non-oncological indications like postmenopausal osteoporosis treatment, established osteoporosis treatment, glucocorticoid induced osteoporosis, male osteoporosis and Paget's 
disease of the bone. The difference is not only in the indication, since the administration regime is also different.

Zoledronate is approximately 2-3 times more potent than pamidronate, it is more or less as potent as alendronate, risedronate and ibandronate, but when it is administrated intravenously, the gastrointestinal adverse effects are avoided and the bioavailability increases, while at the same time, it increases the compliance to $100 \%$. The pharmacokinetics of the drug is very similar to that of the other bisphosphonates. The highest plasmatic concentration is reached just after the infusion, with a posterior descent of approximately $10 \%$ in $4 \mathrm{~h}$, followed by $1 \%$ in the next $24 \mathrm{~h}$. The mean urine excretion of the drug is around $44 \%$ of the administered dose, which means that the bone tissue absorbs more than $50 \%$ from the administered zoledronate.

The HORIZON study (Health Outcomes and Reduced Incidence with Zoledonic Acid Once Yearly Pivotal Fracture Trial) is a multicentric, international, double blind, placebocontrolled trial of postmenopausal women with osteoporosis, whose objective was to show superiority of $5 \mathrm{mg}$ of intravenous zoledronic acid against placebo administrated during a period, not shorter than $15 \mathrm{~min}$. In this study, as in most osteoporosis studies, patients received $1.000-1.500 \mathrm{mg}$ of calcium and 400-1.200 $\mathrm{U}$ of vitamin D. The patients had densitometric osteoporosis or densitometric osteopenia with at least 2 mild to moderate vertebral fractures. (Lyles et al., 2007) Finally, more than 7.700 patients took part in the study and were followed for 3 years; paying special attention to new fractures, bone remodeling biochemical markers and densitometric changes. At the end of the study, the patients that had received zoledronic acid showed a reduction in the vertebral fracture risk of $70 \%$. The reduction was similar for the first and second year of the study, ranging from 60 to $71 \%$. Besides, patients treated with zoledronate showed a reduction of $41 \%$ in hip fracture risk and $25 \%$ in non-vertebral fracture risk. The results of bone density and biochemical bone remodeling markers were also significantly better for the group of patients treated with zoledronic acid. Moreover, the increase in bone mineral density was over $6 \%$ in the lumbar spine and total hip, and over $5 \%$ in the femoral neck. The biochemical markers of bone remodeling, after the first infusion of zoledronic acid, experienced an important decrease, as expected, and they remained stable during the whole study. (Black et al., 2007)

Many patients showed adverse effects during the study, being more frequent in the treatment group. The difference was basically the post-infusion syndrome. This syndrome appeared usually 24-48 hours after the zoledronic acid infusion, just as described by other intravenous bisfosfonates, it happens sometimes, even with the ones administrated orally, and it disappears on the third day post-infusion. The symptoms are light fever, myalgias, flu-like syndrome, headache and/or arthralgias and they disappear with analgesic, nonsteroid anti-inflammatory drugs or paracetamol. The episode appears usually after the first infusion and in seldom cases, after the second one. It shows an incidence with a clear descendent pattern in the later infusions. Some of the patients showed transient renal function deterioration from 9 to 11 days after the infusion, however it did not have any clinical transcendence. (Black et al., 2007)

Probably the most important finding related to the treatment with zoledronate would be the $28 \%$ decrease in mortality independent of the cause, showed in a population of over 2.000 patients with femur fracture. (Lyles et al., 2007)

In conclusion, zoledronate treatment is very efficient for the decrease of vertebral, nonvertebral and hip fractures. It decreases mortality for any cause after a femur fracture. 
Besides, it is a secure treatment that eludes the gastrointestinal adverse events and the bad adherence that are usually seen with other bisfosfonates, but it has to be remembered that, due to its administration route, zoledronate is not for ambulatory use and it has to be administrated very carefully in patients with chronic renal impairment, and those who need to get dental extractions.

\subsection{Cost effectiveness}

Economical evaluation in medicine includes different types of studies that enable us to give the population better care and attention with resources that are limited. Among the many different types of analysis, we can find cost reduction assays, analysis of cost-effectiveness (mostly used), analysis cost-utility and cost-benefit. The cost-effectiveness analysis is probably the easiest to evaluate, since it expresses the monetary units needed to change the units normally used in clinical practice (viral charge, number of fractures avoided or quality adjusted life years, QALY). (Sacristan et al., 2004a, Sacristan et al., 2004b)

Internationally a sanitary intervention is considered to be cost-effective if the additional cost for QALY gained, in comparison with another intervention, is below the 50.000 .00 US\$ and it is not when it is higher than 100.000.00 US\$. In Spain, the amount used is $€ 30.000 .00$ in order to validate the acceptance of interventions. However, there are many authors, who consider this value to be excessively low. (Sacristan et al., 2004a, Sacristan et al., 2004b)

In a review of cost-effectiveness analysis, in which 23 studies were included, and some of which included more than 90 clinical trials, it was demonstrated that the available bisfosfonates in Spain show that the cost of risedronate, compared with no treatment in women with previous fracture is of $€ 43.601 .00$ and for alendronate $€ 49,483$.00. In women without previous fracture the values increase to $€ 61,604.00$ for risedronate and $€ 88,634.00$ for alendronate, both compared with patients not treated. If we consider only patients over 65 years old, treatment with alendronate as well as with risedronate result cost-effective in patients with previous fracture as well as in patients with no previous fracture. As expected, the bigger the population is, the more cost effective is treatment with bisphosphonates. (Van Staa et al., 2007; Fleurence et al., 2007)

It is important to consider that this data is subject to several conditions, such as the comparator and the sample used during the clinical trials, but most importantly the price of the drug. The data used in the Spanish studies presented previously are from 1999, which differ from the actual reality. There are other studies that analyze new bisfosfonates as ibandronate and zoledronate, but not for osteoporosis.

\subsection{Security of bisphosphonates}

These drugs are usually well tolerated, as long as they are taken in a scrupulous way and the intake instructions are followed. Esophageal ulcerations have been known to occur when the drugs are administrated orally and daily. In spite of the good profile that its weekly administration has, it should not be administered to individuals with gastric ulceration or esophageal ulceration, or to those who present pyrosis (heartburn) and require medication. They should not be administrated to pregnant women, or to patients with severe renal function impairment. The intravenous bisphosphonates usually produce acute phase reactions with fever, arthromyalgia and flu like syndrome, that usually disappear by the second administration and that can be relieved with the concomitant use of paracetamol or ibuprofen. Hypocalcaemia can appear more often; therefore it is wise to use calcium and 
vitamin D concomitantly. The renal function has to be controlled before and after the administration of intravenous bisphosphonates.

Avascular necrosis of the jaw, also called osteonecrosis of the jaw is an illness that has worried many physicians, ever since Marx described it for the first time in 2003 and it will be described in detail in another chapter. (Marx, 2003)

\subsection{Long-term effects of the treatment with bisphosphonates: Atypical hip fractures}

Reports associating atypical fractures of the femur with long-term use of bisphosphonates led the initiative of the American Society for Bone and Mineral Research (ASBMR) to form a task force to address key questions related to this finding. The task force defined major and minor features of incomplete and complete atypical femoral fractures and recommended that all major features, including their location in the subtrochanteric region and femoral shaft, transverse or short oblique orientation, minimal or no associated trauma, a medial spike when the fracture is complete, and absence of comminution, be present to appoint a femoral fracture as atypical. Minor features include their relationship with cortical thickening, a periosteal reaction of the lateral cortex, prodromal pain, bilaterality, delayed healing, co-morbid conditions, and concomitant drug use, including bisphosphonates, other antiresorptive agents, glucocorticoids, and proton pump inhibitors. Preclinical data evaluating the effects of bisphosphonates on collagen cross-linking and maturation, accumulation of micro-damage and advanced glycation end products, mineralization, remodeling, vascularity, and angiogenesis provide biologic plausibility to a potential association with long-term use of bisphosphonates. Based on published and unpublished data and the extensive use of bisphosphonates, the incidence of atypical femoral fractures associated with bisphosphonate use for osteoporosis appears to be very low, particularly compared with the number of vertebral, hip, and other fractures that are prevented. Furthermore, a causal association between bisphosphonates and atypical fractures has not been established. However, recent observations imply that the risk rises with increasing treatment duration, and there is concern that lack of knowledge and underreporting may mask the real incidence of the problem. Given the relative infrequency of atypical femoral fractures, the task force recommends that specific diagnostic and procedural codes be created and that an international registry be established to assist studies of the clinical risk factors and optimal surgical and medical management of these fractures. Physicians should be made aware of the possibility of atypical femoral fractures through a change in labeling of bisphosphonates. (Shane et al., 2010)

A study comprising 12,777 Swedish women 55 years of age or older, who sustained a fracture of the femur in 2008 was published recently. Radiographs of 1,234 of the 1,271 women with a subtrochanteric or shaft fracture were reviewed. Fifty-nine patients with atypical fractures were identified. The relative and absolute risk of atypical fractures associated with bisphosphonate use was estimated by means of a nationwide cohort analysis. The 59 case patients were also compared with 263 control patients who had typical subtrochanteric or shaft fractures. The cohort analysis showed an age-adjusted relative risk of atypical fracture of 47.3. The increase in absolute risk was 5 cases per 10,000 patient-years. A total of $78 \%$ of the fractured patients and $10 \%$ of the controls had received bisphosphonates (multivariable-adjusted odds ratio of 33.3). The risk was independent of coexisting conditions. After drug withdrawal, the risk diminished by $70 \%$ per year since the last use (odds ratio, 0.28; 95\% CI, 0.21 to 0.38). (Schilcher et al., 2011) 


\subsection{Biological agents}

The illnesses that provoke bone loss, like osteoporosis, derive from the imbalance in the cycles of bone remodeling favoring bone resorption. The receptor activator of the nuclear factor $\mathrm{kB}$ (RANK), a member of the tumor necrosis factor (TNF) family proteins, and its ligand (RANKL) are fundamental for differentiation, activation and survival of osteoclasts and, therefore, basic mediators of the regulation of bone remodeling. (Anderson et al., 1997; Burgess et al., 1999; Lacey et al., 1998) It has been demonstrated that the signaling of the RANKL is involved in the pathophysiology of many bone loss illnesses, such as primary and many secondary osteoporoses. RANKL production is increased when estrogen is decreased. (Eghbali-Fatourechi et al., 2003) This condition occurs in menopause and in circumstances of hormonal ablation, and leads to an increase in bone resorption. In animal studies with knockout mice lacking RANKL, an absence of osteoclast can be seen, and consequently an increase in bone density. (Kong et al., 1999)

\subsection{Denosumab}

Denosumab, a fully human monoclonal IgG2 antibody to RANKL imitates the effects of osteoprotegerine (OPG), endogenous inhibitor of RANKL blocking bone resorption. Denosumab presents a much longer half-life and it is highly specific since it does not bind to other members of the TNF family, including TNF, TNF-related apoptosis-inducing ligand, or CD40 ligand. (Bone et al., 2008; Kearns et al., 2008; Kostenuik et al., 2009) The binding of denosumab to RANKL prevents rank activation and inhibits the formation, activation and survival of osteoclasts.

Comercial denosumab comes as a sterile, colorless solution intended for subcutaneous injection. It comes ready for administration in a $60 \mathrm{mg} / \mathrm{ml}$ syringe-vial. The prefilled syringe drug product contains denosumab at $60 \mathrm{mg} / \mathrm{mL}, 17 \mathrm{mM}$ sodium acetate, $4.7 \%$ sorbitol, and $0.01 \%$ polysorbate 20 , at a $\mathrm{pH}$ of 5.2 , filled to a target deliverable volume of $1.0 \mathrm{~mL}$.

\subsubsection{Pharmacodynamics and pharmacokinetics}

The pharmacodynamic profile of denosumab appeared alike across all the subject populations studied. So far it has been studied in healthy postmenopausal women (including a Japanese population), healthy men $\geq 50$ years of age, subjects with advanced cancer and bone metastases (breast cancer, other solid tumors [excluding lung], and multiple myeloma), and subjects with rheumatoid arthritis. The results indicate that SC administration of $60 \mathrm{mg}$ denosumab causes a quick reduction in bone resorption within 6 hours, assessed by the marker C-telopeptide of type 1 collagen (CTX1) in serum (approximately 70\% reduction), with an approximately $85 \%$ reduction occurring by 3 days.

Serum CTX1 reductions were maintained for 6 months after the $60-\mathrm{mg}$ dose, with the serum CTX1 reductions partially attenuated from a maximal reduction of $\geq 87 \%$ to reductions of approximately $45 \%$ or greater (range $45 \%$ to $80 \%$ ), reflecting the reversibility of its effects on bone remodeling. The pharmacokinetics following IV or SC administration of denosumab has been studied at doses up to $3 \mathrm{mg} / \mathrm{kg}$ or $210 \mathrm{mg}$ in various populations, including all those described earlier. Following subcutaneous administration, denosumab exhibits dose dependent, nonlinear pharmacokinetics over a wide dose range (as observed for other monoclonal antibodies). Nevertheless, dose-proportional increases in exposure were observed for doses $\geq 60 \mathrm{mg}$, consistent with saturable and non-saturable mechanisms of elimination. Its bioavailability is approximately $60 \%$ after SC injection. No accumulation in 
serum denosumab concentrations was observed with repeated doses of $60 \mathrm{mg}$ every 6 months. There is no evidence that the rare (approximately $0.5 \%$ of treated subjects) and transient development of binding antibodies to denosumab influences its pharmacokinetics or pharmacodynamics. Changes in serum calcium levels following administration of denosumab are not related to the extent of exposure. (Yonemori et al., 2008; Perez-Edo, 2011)

\subsubsection{Denosumab in human clinical trials}

Information is available from 44 clinical trials in healthy adults and patients with osteoporosis (approximately 13,500 subjects), bone loss associated with hormone-ablation therapy (approximately 1,900 subjects), rheumatoid arthritis (approximately 200 subjects), advanced cancer (multiple myeloma and advanced malignancies involving bone [approximately 7,800 subjects]) and giant cell tumor of the bone (approximately 260 subjects) collected between June 2001 to November 2010.

In the Denosumab Fortifies Bone Density (DEFEND) trial, a phase III randomized, placebo controlled study, of 332 postmenopausal women with osteopenia and stratified according to the beginning of menopause $(<5$ years, $>5$ years), denosumab demonstrated a significant increase in lumbar BMD (6.5\%) at 24 months, compared with placebo (-0.6\%). It also increased BMD in other locations as total hip, distal third of the radius, and whole body ( $\mathrm{p}>$ 0.001 ) in the two patients' strata. The incidence of adverse effects was similar between the placebo group and the denosumab group. (Bone et al., 2008)

In a comparative clinical trial, the DECIDE (Determining Efficacy: Comparison of Initiating Denosumab vs. Alendronate) trial, comprising 1,189 postmenopausal women with low BMD (T-score: $\leq-2 \mathrm{SD})$, patients were randomized 1:1 to receive subcutaneous denosumab (60 mg every 6 months) plus oral alendronate placebo weekly or oral alendronate weekly $(70 \mathrm{mg})$ plus a subcutaneous denosumab placebo injection every 6 months. Denosumab increased total hip BMD when compared to alendronate (3.5\% vs. $2.5 \%, \mathrm{p}<0.00001)$. A greater increase in BMD could be seen with denosumab than with alendronate in other locations, as in the trochanter $(4.5 \%$ vs. $3.5 \%)$, distal radius (1.1\% vs. $0.6 \%)$, lumbar spine $(5.3 \%$ vs. 4.2 $\%)$ and femoral neck ( $2.2 \%$ vs. $1.6 \%) ; \mathrm{p}<0.0003$. The safety profile was similar for the two groups. No patient included in the study developed antibodies against denosumab. (Brown et al., 2009)

Another phase III, multicenter, double blind study, called STAND (Study of transitioning from Alendronate to Denosumab) was performed to evaluate the effect of denosumab in patients who were receiving alendronate. Five hundred four postmenopausal women $\geq 55$ years of age with a BMD T-score of <-2.0 and >-4 SD, who were receiving weekly oral alendronate for at least 6 months, were randomized and treated for $44 \pm 33$ months. Changes in BMD and bone biochemical markers were evaluated. At 12 months the group receiving denosumab (but previously treated with alendronate) showed a significantly higher increase in total hip BMD compared to those still receiving alendronate $(1.9 \%$ vs. $1.05 \% ; \mathrm{p}<0.00012)$. Significantly higher BMD increases with denosumab compared with alendronate were also seen at 12 months at the lumbar spine, femoral neck, and distal radius (all $\mathrm{p}<0.0125)$. The adverse events and serious adverse events were similar in both groups of treatment. (Kendler et al., 2010)

Finally, the main phase III trial, the FREEDOM (Fracture Reduction Evaluation of Denosumab in Osteoporosis every 6 Months) trial, comprised 7,868 postmenopausal women with osteoporosis with a BMD T-score between $<-2.0$ and $>-4$ SD and evaluated the efficacy in 
fracture reduction of denosumab. The patients received $60 \mathrm{mg}$ subcutaneous denosumab or placebo every 6 months for 36 months. Around 23\% of the patients had a previous vertebral fracture. The patients' retention rate in the study was $83 \%$. The new fracture relative risk reduction was $68 \%$ ( $2.3 \%$ vs. $7.2 \%$; p $<0.0001)$ for vertebral fractures, $20 \%(6.5 \%$ vs. $8.0 \%)$ for non-vertebral fractures and $40 \%(0.7 \%$ vs. $1.2 \%)$ for hip fractures. As compared with subjects in the placebo group, subjects in the denosumab group had a relative increase of $9.2 \%$ in bone mineral density at the lumbar spine and $6.0 \%$ at the total hip at 36 months. There were no significant differences between subjects who received denosumab and those who received placebo in the total incidence of adverse events, serious adverse events, or discontinuation of study treatment because of adverse events. No cases of osteonecrosis of the jaw were observed in either group. (Cummings et al. 2009)

In conclusion, denosumab offers a highly effective alternative to the treatment of osteoporosis by decreasing bone resorption and increasing bone mineral density through the inhibition of RANKL.

\subsubsection{Cost effectiveness studies of the treatment with denosumab}

One of the clear advantages of denosumab is its administration route and dosage. A subcutaneous injection every 6 months is very comfortable and increases the adherence to treatment. This finding is very important when establishing the cost-effectiveness advantages of any treatment since fracture prevention is improved when adherence is optimal. In order to establish the cost-effectiveness of denosumab compared to generic alendronate, branded risedronate, strontium ranelate and no treatment in a Swedish setting, Jönsson et al, designed a Markov cohort model and followed them for 5 years. The mean age of the Typical Swedish patient population is 71 years old, with a mean BMD T-score of $\leq 2.5$ SD and a prevalence of morphometric vertebral fractures of $34 \%$. Treatment persistence and residual effect after discontinuation was assumed to be equal to the time on treatment. Persistence with the comparators and with denosumab was derived from prescription data and a persistence study, respectively. The base-case incremental cost-effectiveness ratios were anticipated at $€ 27,000$, $€ 12,000$, $€ 5,000$, and $€ 14,000$, for denosumab compared with generic alendronate, risedronate, strontium ranelate, and no treatment, respectively. Fracture and unit costs, as well as mortality rates for the general population were based on data from 2008 . Suboptimal persistence had the greatest impact in the comparison with generic alendronate, where the difference in drug cost was larger. They concluded that persistence improvement impacts positively on cost-effectiveness increasing the number of fractures prevented in the population targeted for osteoporosis treatment. (Jonsson et al., 2011) In another similar study, denosumab was cost effective compared with all other therapies. In particular, denosumab was found to be cost effective compared with branded alendronate and risedronate at a threshold value of $€ 30,000$ per QALY and denosumab was dominant (lower cost and greater effectiveness) compared with risedronate from the age of 70 years in women with a T-score of 2.5 or less and no prior fractures. (Hiligsmann \& Reginster, 2011)

\section{Anabolic agents}

\subsection{Fluoride}

Fluoride is the anion F-, a monovalent ion (-1 charge). At high doses it can be lethal to humans. At low doses, 1 to $2 \mathrm{mg}$ per day, it prevents dental caries. At intermediate doses, 
ranging from 8 to $80 \mathrm{mg}$ daily, skeletal fluorosis can develop. These doses are not so rare, they can be found in some regions with high fluoride levels in well waters or in some industrial settings. It was thought to be a therapeutical agent after observing the osteosclerosis effect at high doses. (Heaney, 1994)

Many years ago, endemic fluorosis was described in patients living in regions with high fluoride water levels or grounds where vegetables and tea were cultivated, like some places in India. Moreover some observations were published describing a low fracture incidence in patients living in areas with high fluoride levels. It was used for the treatment of osteoporosis for the first time in 1961. It was approved for the use of osteoporosis prevention in several countries in Europe, but it never got the approval from the American Federal Drug Administration (FDA). (Pandey \& Pandey 2011; Turner, 1996)

\subsubsection{Pharmacokinetics}

Two different types of compounds have been used for the treatment of osteoporosis: sodium fluoride and monofluorophosphate. Sodium fluoride could be found as capsules or tablets with an enteric protection. A more recent preparation is the sustained release formulation. The ion equivalences usually used were: monofluorophosphate $200 \mathrm{mg}$ containing 16,4 mg of fluoride and sodium fluoride $50 \mathrm{mg}$ containing 22,6 mg if the ion. (Watts, 1999)

Absorption and bioavailability of fluoride preparations depend on their formulation. Thus sodium fluoride is quickly absorbed in the stomach with maximum plasma fluoride levels 30 minutes after ingestion with almost a $100 \%$ bioavailability, while sodium monofluorophosphate absorption is slower with a bioavailability around $65 \%$. It is cleared by the kidney and about $50 \%$ of absorbed fluoride is deposited in the skeleton. Its distribution is not homogeneous since higher amounts are deposited in areas with high bone remodeling rate, such as trabecular bone. (Ekstrand \& Spak, 1990)

\subsubsection{Mechanism of action}

Fluoride increases bone formation increasing osteoblasts proliferation, without altering their differentiation. The molecular basis of this mitogenic action is not known, but there are several hypotheses. The most popular one indicates that fluoride induces an increase in tyrosine phosphorilation of signaling proteins of the mitogenic process. Besides this effect over the osteoblastic cells, fluoride modifies the crystallization of the bone tissue. Thus replacing hydroxylic radicals of hydroxyapatite, forming fluoroapatite, a compound with a lesser structural stability and more resistance to osteoclastic resorption. (Marie et al., 1992)

\subsubsection{Effect of fluoride in bone mineral density and fracture risk reduction}

Results from studies evaluating the effect of fluoride compounds on BMD agree that this agent increases lumbar spine BMD in a consistent and linear manner. The increases in spinal BMD vary between 2.3 and $9 \%$ annually. A recent meta-analysis establishes the mean increase of spinal BMD in $8.1 \%$ at two years and $16.1 \%$ at four years, when comparing it to placebo. The increase in BMD depends on the doses, formulation and fluoride compound used. An interesting finding among all the trials is that there are $25 \%$ of patients considered as non-responders, since they did not experience any change in BMD during the fluoride treatment. (Heaney, 1994; Haguenauer et al., 2000a)

The results of the trials that have studied the effect of fluoride in fracture risk reduction are inconclusive. Some studies have demonstrated the decrease in the incidence of vertebral 
fractures with monofluorophosphate, (Reginster et al., 1998) or sodium fluoride treatment,(Farrerons et al., 1997) while other studies, using the same preparations and doses, failed in doing so. Vestergaard et al, in 2008 published a meta-analysis including 25 different studies and concluding that in spite of the BMD increase in spine and femur, fluoride treatment did not reduce significantly vertebral risk of fracture. (Vestergaard et al., 2008) Moreover, another meta-analysis goes even further and establishes the increase in fracture risk with increasing doses at four years. (Haguenauer et al., 2000a; Haguenauer et al., 2000b)

\subsubsection{Toxicity}

The adverse events seen with fluoride treatment are varied. The most frequent ones are gastrointestinal symptoms and acute lower extremities pain. The frequency and intensity of these effects is dose and preparation dependant. Gastrointestinal symptoms include dyspepsia, epigastralgia, nausea and vomiting, and they appear in $10 \%$ to $40 \%$ of patients. Lower extremity pain is quite common also, appearing in around $15 \%$ of patients, especially in those patients receiving high doses of sodium fluoride or monofluorophosphate. Some authors have established a relationship between these pains and development of stress fractures. (O'Duffy et al., 1986)

Finally, bone biopsies have demonstrated that patients treated with fluoride develop an abnormal bone, consistent with an increase of trabecular width, volume and trabecular surface covered with osteoid material which can be seen inside mineralized bone. When analyzing dynamic histomorphometric indices, a reduction in tetracycline labeling and an extension in the mineralization interval can be seen. Both findings indicate a mineralization defect. (Lundy et al., 1995)

\subsection{Parathyroid hormone and analogs}

Among the many therapeutic options teriparatide or recombinant human PTH (1-34), occupies an important place. It is classified into a group of anabolic bone-forming drugs as opposed to the anti-resorptive or catabolic. Teriparatide is given as daily subcutaneous selfadministered injections.

It induces de novo bone formation by increasing the rate of bone turnover in favor of formation. The treatment with teriparatide increases trabecular connectivity and cortical bone thickness. (Dempster et al., 2001) Teriparatide improves bone mechanical properties resulting in a significant decrease in vertebral and non-vertebral fractures in postmenopausal women with osteoporosis, male osteoporosis and corticosteroid-induced osteoporosis. (Keaveny et al., 2007) That is why its use is considered appropriate mainly in patients at high risk of fracture and in those who have failed previous treatments. (Hodsman et al., 2005)

The fundamental physiological action of parathyroid hormone (PTH) is the maintenance of calcium homeostasis to maintain nearly constant concentrations through the tubular resorption of calcium by stimulating calcium absorption in the bowel by vitamin $\mathrm{D}$, increasing renal 1- $\alpha$ hydroxylase.

The effect exerted by PTH on the skeleton is complex. High levels of PTH observed in primary and secondary hyperparathyroidism, leading to increased bone resorption by its action on osteoclasts, produce secondary osteoporosis. In contrast, low levels increase the osteoblastic activity of bone formation. This would contrast with the desired effect by 
administering PTH as a treatment for osteoporosis. However, it was observed that the action of the hormone on bone varies if administration is continuous (emulating persistently high levels of hyperparathyroidism) that induce catabolic effects on bone, or intermittent (as given in treatment) which also increases resorption as well as formation of bone.

\subsection{Teriparatide (1-34 parathohormone)}

The first available indication for teriparatide was the treatment of established osteoporosis in postmenopausal women. Of the various existing studies on this drug, the FPT (Fracture Prevention Trial) is the most important. It compared teriparatide at doses of 20 or $40 \mu \mathrm{g} /$ day versus placebo in 1637 postmenopausal women with vertebral fractures. Patients receiving teriparatide achieved significant reductions in the rate of new vertebral and non-vertebral fractures. They also produced an increase in lumbar and femoral neck bone density. Although $40 \mu \mathrm{g} /$ day achieved greater effects on BMD, fracture risk was not significantly different between the two doses, while the higher dose was less tolerated $(11 \%$ of withdrawals due to adverse effects with $40 \mu \mathrm{g}$ /day versus $6 \%$ with $20 \mu \mathrm{g} /$ day or placebo). The dose of $20 \mu \mathrm{g} /$ day showed a reduction in vertebral fracture risk of $65 \%$ and a non-hip non-vertebral fracture risk reduction of $35 \%$. This study was initially planned to last for 36 months, but it was stopped when patients had completed an average of 21 months for security measures due to osteosarcomas observed in drug toxicity studies in rats. (Neer et al., 2001) However, in other studies it became clear that this finding occurred only in young rats treated with high doses of PTH. (Vahle et al., 2004) Moreover, no cases have been reported in humans.

A subgroup of patients were followed for up to 18 months after cessation of treatment. The subgroup of women who had received teriparatide showed a persistent $40 \%$ reduction in vertebral fracture risk at 18 months compared with placebo. These results suggest that the benefit on the incidence of non-vertebral fractures persist once it has been stopped. (Lindsay et al. 2004)

\subsubsection{Combination therapy: Teriparatide plus antiresorptives}

Although currently bisphosphonates are the gold standard in the treatment of osteoporosis, there are several trials that have evaluated if the association of teriparatide and BP has any beneficial effect. The studies suggest that if both drugs are administered simultaneously, bisphosphonates do not enhance, but on the contrary, seem to blunt the anabolic effect of teriparatide.

Finkelstein et al. also carried out a study in men with three groups, receiving PTH (1-34), alendronate or the combination of both. In this last group, PTH (1-34) was started at month six. All three groups were followed for 30 months. Spine BMD as measured by DXA and quantitative computed tomography. BMD was increased to a greater extent in the PTH group than in the alendronate or the combination group. Thus, these studies show no evidence of synergy between PTH and alendronate. Furthermore, alendronate may impair the anabolic activity of PTH. It is hypothesized that PTH is less effective when bone turnover is suppressed. (Finkelstein et al. 2003)

\subsubsection{Teriparatide in patients previously treated with antiresorptives}

Once the antagonistic effect of antiresorptives and teriparatide was observed a study was conducted to evaluate the response of teriparatide in patients previously treated with 
antiresorptives. The EUROFORS study was a prospective, open-label, randomized trial of 865 postmenopausal women with established osteoporosis and was designed to investigate various sequential treatments of teriparatide over 24 months. Patients were classified into various groups depending on their previous treatments. The results of the BMD changes and biochemical markers of bone formation showed that treatment with teriparatide induces positive effects on bone mass and osteoblast function regardless of previous longterm exposure to antiresorptive therapies in postmenopausal women with established osteoporosis.

Duration of antiresorptive therapy and elapsed time between stopping previous therapy and starting teriparatide did not affect the BMD response at any skeletal site. The skeletal responses at the lumbar spine were similar among previous antiresorptive therapy groups at each time point during the study, although previous users of etidronate showed a higher increase, probably reflecting its weaker anti-remodeling activity. At month 6, total hip and femoral neck BMD significantly decreased in the previous alendronate subgroup, and total hip BMD significantly decreased in the previous risedronate subgroup. Total hip and femoral neck BMD was numerically decreased from baseline in all other subgroups at 6 months. However, this transient decrease was reversed with longer teriparatide treatment. All subgroups showed a statistically significant increase in BMD compared with baseline after 18 and 24 months of treatment, and without differences between the groups at any time point in the study. (Obermayer-Pietsch et al., 2008)

\subsubsection{Sequential therapy}

In another non-randomized study, 59 postmenopausal women with osteoporosis previously treated with raloxifene or alendronate for 18-36 months, were given 18-month treatment with teriparatide. Changes in BMD and bone-turnover markers were assessed. Women who had previously been treated with alendronate had a late increase in bone-turnover markers with values lower than one third those of patients who had previously received raloxifene. During the first 6 months there were significant differences in the increase in BMD at the lumbar spine and hip. Women previously treated with raloxifene had a greater increase in BMD at the two locations. At 18 months of treatment in the lumbar spine significant differences remained in favor of prior treatment with raloxifene, but in the hip differences were not significant. This demonstrates that treatment with teriparatide increases bone turnover in patients previously treated with raloxifene or alendronate, but this increase is greater and earlier in raloxifene pretreatment group. (Ettinger et al., 2004)

\subsubsection{Corticosteroid-induced osteoporosis and male osteoporosis}

There are also trials showing efficacy of teriparatide in the treatment of glucocorticoidinduced osteoporosis. In a randomized, double blind trial, 428 patients of both sexes aged between 22 and 89 years who had received corticosteroids for at least 3 months were randomized to receive alendronate $10 \mathrm{mg} /$ day or $20 \mu \mathrm{g}$ /day of teriparatide for 18 months. After 12 months the total femur BMD was higher in the teriparatide group and at the end of study there were less vertebral fractures in the teriparatide group. (Saag et al., 2009)

Teriparatide has also been used in men with osteoporosis. The study compared men with idiopathic or secondary osteoporosis receiving teriparatide vs. placebo. The study showed increases independently of gonadal status and other factors in the teriparatide group. (Orwoll et al., 2003) 


\subsubsection{Side effects}

In general, teriparatide, recombinant human PTH (1-34), injections are well tolerated. It is cleared from the circulation within four hours of subcutaneous administration. A daily injection is necessary and transient redness at the injection site has been noted. Headache and nausea occur in less than $10 \%$ of subjects receiving a daily dose of $20 \mu \mathrm{g}$ Mild, early, and transient hypercalcemia can occur, but severe hypercalcemia is rare. Increases in urinary calcium (by $30 \mu \mathrm{g}$ per day) and serum uric acid concentrations (by 13\%) are seen but do not appear to have clinical consequences.

In conclusion, teriparatide is a suitable and efficient treatment option for osteoporosis. It is effective in several clinical problems, such as male osteoporosis or corticosteroids induced osteoporosis.

\subsection{1-84 Parathormone}

Intact PTH (PTH 1-84) has been described as having a positive effect on bone micro architecture and a reduction in the risk of new fractures due to a bone-forming mechanism. (Rosen \& Bilezikian, 2001)

1-84 PTH (as well as 1-34 PTH) acts through its receptor, exerts its action in bone through osteoblasts by modulating the levels of cAMP by activating secondary messengers it acts on the osteoclast bone resorptive process. In collagen tissue, PTH in high and sustained doses inhibits its synthesis, but at low doses and used intermittently, through the action of IGF-1, it stimulates its synthesis.

PTH also increases the local synthesis of IGF-1, which may explain its anabolic effect in bone tissue. Other actions of PTH include modulation of TGF B1 and the production of prostaglandins that may contribute to bone formation, acting on the pre-osteoblast differentiation stage. And it is through the IGF-1 that it inhibits apoptosis.

This mechanism distinguishes the effect of treatment with PTH of other treatments that inhibit the resorption stage of bone remodeling acting on osteoclast (like bisphosphonates). The ability of PTH to act directly on the osteoblast, the cell that directly produces new bone, drives in the enhancement of production of new bone with consequent gain in bone mineral density and fracture risk reduction.

\subsubsection{Clinical use of 1-84 PTH}

Hodsman et al. conducted a study in 217 postmenopausal women with osteoporosis, with a mean age of 64.5 years, who were randomly classified into different groups receiving placebo or PTH 1-84 at doses of 50,75 , or $100 \mathrm{mcg}$. The primary endpoint was change in $\mathrm{BMD}$ at the lumbar spine after 1 year of treatment. The results showed a mean increase in BMD of $3.0 \%, 5.1 \%$ and $7.8 \%$ in the group receiving 50,75 and $100 \mathrm{mcg} /$ day of $1-84 \mathrm{PTH}$ respectively, compared with placebo, with all increases clearly statistically significant, whereas in the control group receiving calcium and vitamin $\mathrm{D}$, there was an increase of $0.9 \%$ that did not reach statistical significance. The increase in BMD obtained by the group that received $100 \mathrm{mcg}$ was statistically significant with respect to the other two groups receiving $\mathrm{PTH}$, passing from a T-score of -3.2 at baseline to -2.8 at the end of treatment. In contrast there were no statistically significant differences in BMD at the hip. (Hodsman et al., 2003) The pivotal clinical trial with 1-84 PTH is the TOP (Treatment of Osteoporosis) study. It comprised 2,532 postmenopausal women with osteoporosis receiving PTH (1-84) or placebo. The follow up was up to 18 months. The main goal was the reduction in vertebral fracture 
risk. Mean age of patients in the study was 64 years, and of them, 19\% had at least one vertebral fracture. After 18 months, the increase in BMD at the lumbar spine in women treated with PTH (1-84) was 7\% compared with the placebo group. The risk of new vertebral fractures decreased by $66 \%$ in the group treated with PTH. Hypercalcemia was observed in $28.3 \%$ of treated women, compared to $4.7 \%$ in the control group. (Greenspan et al., 2007)

\subsubsection{Combination and sequential therapy}

The effects of concurrent or sequential therapy with PTH and antiresorptive agents have been studied. Black et al. compared the effects of PTH (1-84), alendronate, or both in combination in postmenopausal women in the study PaTH. In this study, 238 postmenopausal women were randomized with ages comprised 55-85 years with a T-score $<-2.5$ or a T-score $<-2$ and with at least one risk factor or additional fracture. Initially there were 3 groups receiving: PTH (1-84) $100 \mathrm{mcg} /$ day + placebo $(\mathrm{n}=119)$, alendronate $($ ALN) $10 \mathrm{mg} /$ day + placebo $(\mathrm{n}=60)$ and PTH $(1-84) 100 \mathrm{mcg} /$ day + ALN $10 \mathrm{mg} /$ day $(\mathrm{n}=59)$. All participants received daily calcium 500mg + vitamin D (400UI) supplements. (Black et al., 2003)

At one year, spine DXA had increased in all three groups. There was no difference in spine DXA between the PTH group and the combination group. However, the PTH group had a significantly greater increase in volumetric BMD of the spine on quantitative $\mathrm{CT}$ than the alendronate and combination groups. Volumetric trabecular lumbar BMD increased with respect to baseline by $26 \%, 13 \%$ and $11 \%$ in the PTH alone, PTH and alendronate and alendronate group respectively at 12 months. Similarly, volumetric trabecular BMD of the total hip increased by $9 \%, 6 \%$ and $2 \%$ respectively in the 3 groups.

\subsubsection{Effects on bone architecture}

In spite of the facts of all these studies previously published, data about what was happening in bone was lacking. Recker et al. studied bone biopsies from iliac crest from postmenopausal osteoporotic women who received placebo $(n=8)$ or $100 \mathrm{mcg}$ PTH(1-84) for $18(n=8)$ or $24(n=7)$ months to assess cancellous and cortical bone formation and structure. Using micro CT and histomorphometry at 18 months, cancellous bone volume (BV/TV) measured was $45-48 \%$ higher in subjects treated with $\mathrm{PTH}(1-84)$ versus placebo, and also resulted in a higher trabecular number (Tb.N) and thickness. The higher Tb.N appeared to result from intra-trabecular tunneling. Connectivity density was higher and structure model index was lower, indicating a better connected and more plate-like trabecular architecture. Cancellous bone formation rate (BFR) was 2-fold higher in PTH (1-84)-treated subjects, primarily because of greater mineralizing surface. (Recker et al.,2009)

\subsubsection{Adverse effects}

The physical effects produced by PTH 1-84 are in most cases mild. The most common is hypercalcemia, present in $28 \%$ of women treated vs. $4.6 \%$ in the placebo group and hypercalciuria, $46 \%$ versus $23 \%$ respectively. However, the number of withdrawals of treatment due to this cause was rare in published clinical trials (two patients in the PaTH study and six patients in the TOP study) and generally the effect was controlled by removing the supplements of calcium and vitamin D. Although it is believed that hypercalcemia could slightly modify electrocardiographic studies decreasing the QT interval without significant changes or minimal changes in heart rate, PR interval or QRS duration and axis, no differences between groups were observed. Other reported side 
effects, although often not as important as the ones mentioned above, were nausea and vomiting. Fisher et al, reported a study with 344 rats treated with nearly life-long daily teriparatide, and found an increased risk of osteosarcoma. Nevertheless, to date there is no reported increase in prevalence of osteosarcoma in humans treated with neither teriparatide nor PTH 1-84, and no association has been found between primary hyperparathyroidism and osteosarcoma. Recently, Tashiian et al. reported that they had not collected a single case of osteosarcoma in humans, following the prescription of more than 250,000 treatments with PTH, 1-34 and 1-84 after follow-up of patients who participated in the studies with PTH 1-84 in the 80's. (Tashiian \& Goltzman, 2008)

\section{Dual action agents}

\subsection{Strontium ranelate}

Strontium ( $\mathrm{Sr})$ is a chemical element with an atomic number 38. It is an alkaline earth metal and was isolated for the first time, as an impure substance, in 1808 in a Scottish city named "Strontain" from which this element received its name. It is in this city where strontium is found in higher concentrations than usual $(73 \mathrm{~g} / \mathrm{kg})$. The earth cortex contains $0.042 \%$ of strontium and is as abundant as chloride and sulfur. It can also be found in rocks, dust, carbon and oil, as well as in some foods as cereals, green vegetables and milk. In marine water, strontium is the most abundant trace element, reaching values of $8 \mathrm{mg} / \mathrm{L}$. (Cabrera et al., 1999) In its natural state, called stable strontium, this element is not radioactive and it is harmless. The only compound harmful for the human being is strontium chromate, and due to chrome not to strontium. (Levy et al., 1986) The therapeutic potential of strontium was discovered around 1940, when strontium-89 was used as an analgesic agent in bone metastases from prostate cancer. (Giammarile et al., 1999; Saarto et al., 2002) Afterwards this isotope, together with strontium-88, have been used as markers for calcium absorption. (Cabrera et al., 1999)

\subsubsection{Pharmacological characteristics}

The main entrance of strontium into the body is through the gastrointestinal system. The skin and the lungs can also absorb it. Its gastrointestinal absorption varies with age and has a very high variability in infants. In the elderly, the fluctuation is about $10 \%$. A number of absorption mechanisms have been proposed, beginning with the passive mechanisms and diffusion, to transporter mediated absorption, as proposed by Papworth et al. Strontium absorption augments with fasting and it is seriously affected by calcium, phosphorus and other chelating agents in the bowel and its absorption rate is about half of calcium. Other experimental studies have demonstrated that during pregnancy and breast-feeding strontium absorption is increased, reaching a maximum during breast-feeding. (Papworth \& Patrick 1970; Papworth \& Vennart, 1984)

Absorption of strontium is dose dependant. Its bioavailability decreases with a lower dose, confirming that, just like calcium, absorption involves passive diffusion, independent of vitamin D levels, as well as saturable active transport, regulated by vitamin D and a facilitated diffusion. (Ardissino et al., 2000) Studies in a variety of animals (i.e. rats or monkeys) demonstrate that the pharmacokinetic data of renelic acid have a high variability. It is estimated that its oral absorption is poor and slow, probably due to a deficient intestinal permeability. (Li et al., 2006) 
Serum concentration of strontium can be affected by the administration together with calcium and with meals. When administered together with 0,5 grams of calcium, strontium relative bioavailability decreased 57\%, 63\% when administered with meals and $71 \%$ when administered with calcium and meals. Due to these absorption difficulties, several studies were conducted in order to determine the best mode of administration. Comparing strontium administration one hour before breakfast and three hours after breakfast to every 12 hours resulted in a decrease of bioavailability of 46 and $55 \%$ respectively. In phase 2 studies no difference was observed between giving strontium 1 gram every 12 hours or 2 grams before bedtime. Thus, to guarantee the best absorption and bioavailability, it is recommended to administer strontium ranelate two hours after dinner. (Leeuwenkamp et al., 1990; Reginster \& Meunier 2003) Vitamin D seems to increase the medications' absorption, though in phase 3 studies it was observed that the influence of vitamin $\mathrm{D}$ did not change strontium availability in more than $10 \%$, which is clinically insignificant. (Ardissino et al., 2000; Leeuwenkamp et al., 1990; Marie, 2003)

Strontium excretion is mainly through renal clearance, and to a lesser extent through feces and sweat. In healthy adults, strontium plasma clearance varies between 9.4 and 11.7 $\mathrm{ml} / \mathrm{min}$, meanwhile the urinary clearance is between 4.0 and $5.4 \mathrm{ml} / \mathrm{min}$. (Papworth \& Vennart, 1984; Leeuwenkamp et al., 1989) In animal studies, the bone tissue strontium content decreased to approximately $50 \%$ at week 6 to 10 after stopping treatment. Renelic acid, given its high polarity, is poorly absorbed and its half-life in animals is about 1 hour, though it varies according to its absorption. In humans, renelic acid excretion is approximately $78 \mathrm{ml} / \mathrm{min}$ and therefore it has a half-life of 2.6 hours. (Li et al., 2006; Leeuwenkamp et al., 1990)

Due to its chemical properties, strontium can form complexes with oral tetracyclines and quinolones, and therefore its administration with these medications is not recommended. Strontium administration together with diuretics could increase its serum concentration around $20 \%$. This effect is greater with thiazide diuretics, furosemide and indapamide, and could be explained by the increase in the strontium tubular re-absorption, together with calcium, which would rise in parallel. Even though this increase in strontium levels is not clinically significant and no dose adjustment is needed. Magnesium and aluminum hydroxide can significantly decrease strontium bioavailability, therefore it is not recommended to take these medications at night, when strontium should be administered. (Leeuwenkamp et al., 1990; Marie, 2003)

\subsubsection{Mechanism of action}

In-vitro, strontium ranelate increases collagen and non-collagen protein synthesis thru mature osteoblasts. The bone forming effects were confirmed with the increase in the replication of pre-osteoblastic cells. This stimulus of the replication of the pre-osteoblastic cells and the increase of collagen and non-collagen proteins are the reason why strontium ranelate is considered as a dual effect bone agent, since it does not only decrease resorption. (Bonnelye et al., 2008) In an in-vitro assay of isolated rat osteoclasts, the pre-incubation of bone slices pre-treated with strontium ranelate, demonstrated a dose dependant decrease in bone resorption activity. In another assay, using chicken bone marrow, a dose dependant decrease in the expression of carbonic anhydrase II and the alpha subunit of the vitronectin receptor could be observed. (Takahashi et al., 2003; Caverzasio, 2008; Bonnelye et al., 2008; Reginster et al., 2003) 
The main mechanism of action that rules bone resorption at a molecular level is the RANK/RNAKL/OPG system described earlier. Concentrations of $0.1 \mathrm{mM}$ to $2 \mathrm{nM}$ of strontium ranelate, decrease the ability of human osteoblasts of inducing osteoclast differentiation, by decreasing expression of mRNA of RANK-L and increasing mRNA expression of OPG, according to the studies done by Brennan et al in 2006. (Close et al., 2006; Chapurlat \& Delmas, 2004)

The human body has a very strict extracellular calcium control mechanism. This control is performed by varied body tissues with the aim of keeping extracellular calcium levels within a narrow range, which is essential for the normal cellular function including muscular contraction, nerve impulse transmission or platelet aggregation, for example. The tissues involved in this task, like the chief cells of parathyroid glands, $\mathrm{C}$ cells of the thyroid glands, renal tubules, the cortical ascending limb of the nephron, the intestinal epithelium and the bone cells like osteoclasts and osteoblasts, express a receptor capable of detecting changes in the extracellular calcium levels and act according to the requirements, these receptors are called calcium receptors or calcium sensing receptors (CaR). (Brown 2003)

Several studies with cell cultures have been able to demonstrate that this receptor can be activated by other divalent cations, including strontium, which just as calcium but with a lower potency can activate the CaR. This means that in the presence of strontium, chief cells of the parathyroid glands will decrease its secretion and that osteoclasts will decrease bone resorption, for example. Numerous assays demonstrate that $0.13 \mathrm{nM}$ strontium plasma levels, like the ones seen in patients treated with $2 \mathrm{~g}$ of strontium ranelate daily, won't affect the $\mathrm{CaR}$ in soft tissues. The effect on osteoclast apoptosis could be related to the activation of the transmembrane receptor attached to phopholipase $\mathrm{C}(\mathrm{CaR})$ and mediated by an independent signaling pathway of IP3-protein kinase C. Some other authors suggest that besides $\mathrm{CaR}$, there are other receptors that can also influence these actions. These receptors could be related to the stimulating effect of strontium on osteoblasts replication in $\mathrm{CaR}$ knockout rats. (Arlot et al., 2008; Brown, 2003)

\subsubsection{Effects on other tissues}

Some studies have demonstrated that strontium ranelate has beneficial effects in tissues other than bone. Taking cartilage for example, strontium ranelate increased basal production of proteoglycans stimulated by insulin growth factor 1 by chondrocytes of young subjects, old subjects and subjects with osteoarthritis. On the contrary, it showed no effect on the proteoglycans production induced by interleukin 1 (IL-1), the stromelycin production stimulated by IL-1 $\beta$ or chondrocytes activity. These findings suggest that strontium ranelate stimulates human cartilage matrix formation in vitro without activating the chondroresorption process. (Henrotin et al., 2001)

\subsubsection{Effect of strontium ranelate in fracture reduction}

It is known that due to the chemical properties of the compound (a higher molecular weight), densitometric values of patients treated with strontium ranelate will be higher than the true values. There are many studies that have measured the influence of the chemical characteristics of strontium on densitometry and have developed some mathematical formulas to remove this influence from the DMO value. These formulas are a little bit complicated and require too much time to put them into practice in the daily practice, 
therefore the utility of these formulas is restricted to almost only research. It is easier and almost accurate to calculate that half of the DMO gained in the first year of treatment with strontium ranelate is due to an increase on BMD and the rest is due to the higher molecular weight on strontium measured by the DXA. (Blake \& Fogelman, 2006b)

Currently we have data from clinical studies comparing strontium ranelate to placebo for fracture prevention for up to five years. Moreover we have data of fracture incidence in patients treated with strontium ranelate for up to 10 years. The phase III pivotal trial was performed in 75 centers distributed through 12 countries worldwide. It was structured in three different clinical trials. The FIRST (Fracture International run-in for Strontium Ranelate) trial mean duration was 101 days $(S D \pm 52)$ and was performed with the objective of normalizing calcium and vitamin D levels of all subjects. From this trial the other two were derived, the SOTI (Spinal Osteoporosis Therapeutic Intervention) trial and the TROPOS (Treatment of Peripheral Osteoporosis) trial. (Reginster \& Meunier, 2003; Reginster et al., 2005) The main propose of these trials was to evaluate the effect of strontium ranelate in axial and appendicular skeleton as well as the tolerability in postmenopausal osteoporotic women. Their main objective was to calculate the reduction in the incidence of new vertebral fractures (SOTI trial) as well as non-vertebral fractures (TROPOS trial). (Reginster et al., 2008) The analysis included 1649 postmenopausal women in the SOTI trial and 5091 patients in the TROPOS trial. In the SOTI trial women were randomized into two groups, a placebo (control) group and another one receiving $2 \mathrm{~g}$ daily of strontium ranelate for a period of four years. In the fifth year, the patients taking placebo switched to strontium ranelate and $50 \%$ of the ones taking strontium ranelate switched to placebo. In the TROPOS trial, all patients remained in their original treatment group during the whole 5 years. The preliminary three-year results showed a vertebral fracture reduction of $41 \%$ with a NNT of 9. Furthermore an increase in BMD of $12.7 \%$ was observed. The vertebral fracture reduction at the end of the forth and fifth year was of $33 \%$ and $24 \%$, respectively. Similar results were obtained from the TROPOS trial where the vertebral reduction rate was 39\% at the end of the third year and $24 \%$ at the end of the fifth year. Regarding the non-vertebral fractures the decrease in the relative risk of fracture with strontium ranelate was $16 \%$ at the end of the third year and $15 \%$ at the end of the fifth. A post-hoc analysis of these data in a subgroup of 1,977 patients with high fracture risk ( $\geq 74$ years old and a T-score of $\leq-2.4)$ showed a vertebral fracture risk reduction of $36 \%$ at the end of the third year and $43 \%$ at the end of the fifth. (Blake \& Fogelman, 2005; Reginster et al., 2007; Moro-Alvarez \& Diaz-Curiel, 2007) Since there is no data showing the fracture reduction risk of strontium ranelate in placebo controlled patients, Reginster et al, compared the fracture incidence between the original strontium ranelate group at the end of the fifth year to the strontium ranelate group followed for ten years. The results are shown in table 2. (Reginster et al., 2010) These results show no statistically significant differences between the incidence of fractures at the end of year 5 or 10. An important fact to bear in mind is that the sample was significantly reduced since at the end of the tenth year, just 233 patients continued in the follow up study.

Another sub study performed by Seeman et al, with patients over 80 years of age showed a reduction in the vertebral fracture risk of $32 \%$ in the third year and $31 \%$ in the fifth year. For peripheral fractures, the reduction in fracture risk was of $31 \%$ in the third year and $27 \%$ in the fifth year, and for hip fractures the risk reduction was 32\% in the third year and $24 \%$ in the fifth. (Seeman et al., 2010; Seeman et al., 2006) 


\begin{tabular}{|c|c|c|c|}
\hline & $\begin{array}{c}5 \text { years with } \\
\text { placebo }\end{array}$ & $\begin{array}{c}5 \text { years with } \\
\text { Strontium ranelate }\end{array}$ & $\begin{array}{c}10 \text { years with } \\
\text { strontium ranelate }\end{array}$ \\
\hline Vertebral fracture incidence & $24.9 \%$ & $18.5 \%$ & 20.6 \\
\hline $\begin{array}{c}\text { Non-vertebral fracture } \\
\text { incidence }\end{array}$ & $20.9 \%$ & $12.9 \%$ & $13.7 \%$ \\
\hline
\end{tabular}

Table 2. Fracture incidence at 10 years. (Reginster et al., 2010)

\subsubsection{Adverse events}

At the end of the third year, in the phase III studies, the only adverse event that showed statistically significant differences compared to placebo was diarrhea, found in $6 \%$ of the patients taking the drug and $3.6 \%$ of the placebo group. Other adverse events found to be more frequent with strontium ranelate, but with no statistically significant difference compared to placebo, were nausea, headache, dermatitis, eczema, and thrombo-embolic events. The latter was studied thoroughly, but no relation to the drug was found. Other studies with high doses of strontium ranelate have been performed in order to investigate thrombo-embolism, but no alteration in coagulation parameters have been found to support the finding in the phase III trial. (Blake \& Fogelman, 2006a; Halil et al., 2007; Liu et al., 2009; Ulger et al., 2010)

At the end of the fifth year some other events were found to be more frequent (with no statistically significant differences compared to placebo) such as memory loss, cognitive impairment and seizures. The rest of the adverse events had the same incidence in the study drug and the placebo group. (Blake \& Fogelman, 2006a; Liu et al., 2009)

Strontium ranelate has been used widely in Europe and there is a rare adverse event reported to be due to treatment with this compound. Reports state that $0 \%$ to $8 \%$ of patients suffer a drug rash with eosinophilia and systemic symptoms (DRESS), which is an allergic reaction to the medication that usually appears between 3 and 6 weeks after starting treatment. This syndrome can be fatal if the medication is not stopped and treatment with glucocorticoids started. (Musette et al., 2010)

\section{Future therapies}

\subsection{Cathepsine K (CatK) inhibitors}

Human cathepsin $\mathrm{K}$ is a 329 amino acid long protein consisting of an N-terminal 15 amino acid long signal sequence, a 99 amino acid long propeptide, and a 215 amino acid long catalytic unit. It shares about $60 \%$ protein sequence identity with cathepsins L, S, V and less than $35 \%$ with cathepsins $\mathrm{F}, \mathrm{O}, \mathrm{B}, \mathrm{H}$, and $\mathrm{W}$. Cathepsin $\mathrm{K}$ is expressed predominantly in osteoclasts and various other multinucleated cells such as giant foreign body cells and Langhans cells. To a lesser degree it is found in macrophages, synovial fibroblasts, and fibroblasts at locations of wound healing or inflammation, chondrocytes, various epithelial cells of the human fetus, adult lung airway epithelium, thyroid epithelium, and possibly at low concentrations in smooth muscle cells. Once the enzyme is synthesized, it is sequestered into lysosomes and can be secreted into the extracellular environment. It is specifically secreted into the resorption lacuna underneath actively resorbing osteclasts where it is responsible for the degradation of the collagen type I dominated organic bone matrix. Thus, similarly to pycnoidisostosis, elimination of cathepsin $\mathrm{K}$ in osteoclasts results in inhibition of bone resorption. Inhibitors of cathepsin $\mathrm{K}$ are suggested to have less of an effect on 
osteoclast-osteoblast interaction, resulting in less inhibition of bone formation, than available bisphosphonate antiresorptive agents. Human cathepsin $\mathrm{K}$ inhibitors have been shown to prevent bone loss in ovariectomized mice without blunting the anabolic action of parathyroid hormone (PTH).

Although no CatK inhibitor is currently marketed for osteoporosis treatment or prevention, studies of three CatK inhibitors for the treatment of osteoporosis have been reported: balicatib, relacatib, and odanacatib.

The most commonly used drugs for the treatment of osteoporosis inhibit osteoclastmediated bone resorption. Osteoclasts are hematopoietically derived multinucleated giant cells that resorb bone by focal attachment and demineralization, followed by the enzymatic degradation of organic bone matrix. The demineralization is achieved by the secretion of acid onto the bone surface. The organic matrix (mainly type 1 collagen, the principal bone matrix protein) is degraded primarily by the enzymatic action of cysteine proteases, particularly cathepsin K (CatK). CatK is the most abundantly expressed cysteine protease in osteoclasts and exhibits collagenolytic activity under acidic conditions. Currently treatment of osteoporosis, like bisphosphonates prevent acid secretion by disruption of the ruffled border and proton pump required for hydrogen ion secretion.

The collagenases of the matrix metalloproteinase family have been considered as the main proteases for the degradation of collagen as they were thought to be the main ones capable of cleaving triple helical collagen. However, matrix metalloproteinase are active at neutral to slightly alkaline $\mathrm{pH}$ values whereas at the site of bone resorption, within the resorption lacuna, acidic $\mathrm{pH}$ conditions prevail. Thus, acidic lysosomal hydrolases were proposed to operate as the main collagen degrading proteases. Previously, only Cathepsins B and L were known. Cathepsins B and L were thought to be the key factors, as both enzymes were known to cleave in the telopeptide region of triple helical collagens. However in the early 1990 's a new cathepsine was identified thanks to DNA clonation techniques. Initially this new cathepsine was identified only in osteoclasts and was called cathepsine $\mathrm{O}$, later its name changed to cathepsine $\mathrm{K}$. This protease exhibited a potent collagenase activity towards the main connective tissue collagens type I and II, and immunohistochemical analyses revealed a predominant but not exclusive expression in osteoclasts. After that, pycnodysostosis, a hereditary form of osteopretosis was related to a low level of Cathepsine K due to a complete deficiency.

\subsubsection{Balicatib}

Balicatib is highly selective for CatK in enzyme assays but has lesser selectivity in living cells. In vitro studies have shown that a basic moiety in its chemical structure results in its accumulation in the acidic environment of the lysosomes at concentrations sufficient to inhibit cathepsins B and L and possibly others. Clinical studies of balicatib have demonstrated BMD increases in postmenopausal women, but treatment was associated with cutaneous adverse events. The first demonstration of the effect of cathepsin $\mathrm{K}$ inhibitors on bone density in humans was seen with balicatib. This trial, published by Adami et al., in an ASBMR meeting in 2009 (Denver, CO, USA) was a multicenter, randomized, placebocontrolled, 12-month, dose-range finding study of 675 postmenopausal women with lumbar spine T-score less than 2.0. In the group that received 50mg of balicatib daily, markers of bone resorption declined by more than $55 \%$ with no decline in markers of bone formation (osteocalcin, bone-specific alkaline phosphatase and N-terminal propeptide of type I 
collagen). The BMD in the lumbar spine increased $4.46 \%$ and $2.25 \%$ in the total hip. Skin reactions, including pruritus and morphea-like changes, were noted in a small number of patients. In a small Japanese trial, intact PTH levels were shown to increase by $50 \%$ with balicatib treatment.

\subsubsection{Relacatib}

Relacatib is a potent but nonselective inhibitor of cathepsins K, L, V, and S for which no clinical information has been published. Administration of relacatib to ovariectomized and control monkeys resulted in an acute and rapid reduction of bone markers, and this effect lasted for up to 2 days depending on the dose delivered.

Due to side effects, especially skin reactions, drug development of all cathepsin K inhibitors has been suspended or slowed down except for odanacatib and currently ONO 5334.

\subsubsection{Odanacatib}

Odanacatib is a powerful, reversible nonpeptidic biaryl inhibitor of cathepsin $\mathrm{K}$ that inactivates the proteolytic activity of cathepsin $\mathrm{k}$. It is synthesized by replacing the P2-P3 amide bond of an aminoacetronintrile dipeptide 1 with a phenyl ring. This results in a powerful, selective inhibitor with the capacity to inhibit cathepsin $\mathrm{K}$ in osteoclasts. (Bromme \& Lecaille, 2009)

Two studies have been carried out to evaluate the efficacy and safety of odanacatib, a phase I study to determine the dose and a phase II study to evaluate the safety and efficacy. In the Phase I study a group of 49 women was used to evaluate a weekly dose. Doses of $5 \mathrm{mg}$, 25 $\mathrm{mg}, 50 \mathrm{mg}$, and $100 \mathrm{mg}$ were used and 12 women were assigned to the placebo group. A group of 30 women was used to evaluate the daily dose. Doses of $0.5,2.5$, and $10 \mathrm{mg}$ were used, with 6 women assigned to the placebo group. All doses were administered in fasting conditions. Odanacatib had a long half-life of between 66 and 93 hours for all the regimes and doses used. The efficacy of weekly, and daily doses in modifying the markers was evaluated. The effect was dose-dependant although not dose proportional. Reductions in resorption markers were greatest for doses $>50 \mathrm{mg}$ weekly and doses $\geq 2.5 \mathrm{mg}$ daily. Maximum suppression was achieved between day 3 and day 5 with the weekly dose and was maintained until the following dose. (Stoch et al., 2009)

The Phase II trial published by Cusick et al in the ASBMR meeting in 2009 (Denver, Co, USA), was a double-blind, randomized, placebo-controlled trial of 12 months duration with an anticipated extension period of 24 months. It included 399 post-menopausal women (postmenopausal (5yr) or bilateral oophorectomy) between 45 and 85 years, with a T-score <2 but not less than -3.5 at any site. Patients were divided into five groups according to the dose: placebo, $3 \mathrm{mg} /$ weekly, $10 \mathrm{mg} /$ weekly, 25mg/weekly and $50 \mathrm{mg} /$ weekly. The changes in BMD at the lumbar spine were assessed and considered a primary objective. Also changes in bone remodeling, changes in BMD in other sites and adverse effects were evaluated. The results showed a dose-dependant increase in BMD in all sites. The greatest increase was obtained with the highest dose. Weekly administration of $50 \mathrm{mg}$ of odanacatib increased bone mass by $5.7 \%$ in the lumbar spine, $4.1 \%$ in the total hip, $4.7 \%$ in the femoral neck, $5.2 \%$ in the trochanter and $2.9 \%$ in the distal third of the radius at 24 months. Resorption markers fell in a dose-dependant manner from the beginning of treatment and remained reduced during the first six months, after which they increased and the differences with placebo disappeared. 
The results of the extension of the phase II study to 36 months (published by Eisman et al at the ASBMR meeting 2009 in Denver, included 169 women who were randomized to odanacatib $50 \mathrm{mg}$ and placebo weekly. In the odanacatib group, BMD continued to increase (lumbar spine 7.5\%, total hip 5.5\%, femoral neck 5.5\% and trochanter 7.4\%). The urine NTX resorption marker was 50\% lower compared with placebo, whereas there were no differences in the BSAP (bone specific alkaline phosphatase) formation marker. At three years, formation markers were not only not reduced, but in fact increased by $18 \%$ over baseline values.

\subsubsection{ONO 5334}

ONO-5334 is a new cathepsin $\mathrm{K}$ inhibitor. There has been a first study to investigate the efficacy and safety of ONO-5334 in postmenopausal osteoporosis. This was a 12-month, randomized, double blind, placebo and active-controlled parallel-group study conducted in 13 centers in 6 European countries. Investigators included 285 postmenopausal women aged 55 to 75 years with osteoporosis. Subjects were randomized into one of five treatment groups: placebo; $50 \mathrm{mg}$ twice daily, $100 \mathrm{mg}$ once daily, or $300 \mathrm{mg}$ once daily of ONO-5334; or alendronate $70 \mathrm{mg}$ once weekly. After a year of follow up all ONO-5334 doses and alendronate showed a significant increase in BMD at the lumbar spine, total hip (except 100 mg once daily), and femoral neck. There was little or no suppression of ONO-5334 on boneformation markers compared with alendronate, although the suppressive effects on boneresorption markers were similar. There were no clinically relevant safety concerns. With a significant increase in BMD, ONO-5334 also demonstrated a new mode of action as a potential agent for treating osteoporosis. This new drug increases the armamentarium not only in cathepsin K inhibitors (the second that seems to be available) but also in osteoporosis treatment. (Eastell et al., 2011)

In conclusion, Cathepsine $\mathrm{K}$ inhibitors are a new family of drugs that increase the armamentarium in the fight against fractures, as the most dangerous effect of osteoporosis. Having the possibility to treat this disease in different points of the resorption pathway is positive and it gives us the possibility to reach a better and easier way to decrease the incidence of fractures.

\subsection{Anti-sclerostin monoclonal antibody}

Sclerostosis is a rare autosomal-recessive disorder. Patients with this disease characterize for having a high bone mass. (Hamersma et al., 2003; Beighton, 1988; Barnard et al., 1980) The study of its etiopatogenesis led to the discovery of sclerostin, a protein that in humans is encoded by the SOST gene. (Balemans et al. 2001; Brunkow et al., 2001) It is classified as a key inhibitor of osteoblast-mediated bone formation. (Poole et al., 2005; Wergedal et al., 2003) Loss-of-function mutations in this gene are associated with sclerosteosis, which causes progressive bone overgrowth and increases in bone mass and BMD.

Another similar disease is van Buchem disease, which is a milder form of sclerostosis and is caused by a deletion downstream of this gene, with a consequent reduced sclerostin expression. SOST gene knock out mice don't produce sclerostin and have a high bone mass, confirming the effect of this protein on bone mass and BMD. Besides the increase in bone mass and BMD taking place from sclerostin deficiency, there have been no reports of fractures in individuals with sclerosteosis or van Buchem disease. (Hamersma et al., 2003; Wergedal et al., 2003) 
Sclerostin binds to low-density lipoprotein receptor-related protein (LRP) 5/6 and blocks Wnt-signaling, negatively regulating bone formation and in that way, inhibiting osteoblast differentiation, proliferation, and activity. (Baron \& Rawadi 2007) Thus, the inhibition of sclerostin was thought to have therapeutic potential in treating human bone metabolism defects such as systemic bone loss, focal bone loss, fracture healing, and orthopedic procedures where increases in bone formation, bone mass, bone mineral density (BMD), and consequently bone strength, are sought-after. (Ott, 2005)

\subsubsection{Sclerostin inhibition}

Rats treated with a sclerostin antibody experience a reversal of estrogen deficiency induced bone loss at several skeletal sites. Additionally, an increase in bone mass and strength is observed in treated rats compared with controls. Similar results were observed in treated monkeys. In models of fracture healing in mice and rats, treatment with a sclerostin antibody increased bridging and bone strength at sites of fracture, resulting in enhanced bone healing compared with controls. (Padhi et al., 2011)

AMG 785 is a high affinity immunoglobulin G2 (IgG2) monoclonal antibody generated by humanizing a mouse sclerostin monoclonal antibody that neutralizes sclerostin. The first-inhuman single-dose study in healthy men and postmenopausal women was performed to evaluate pharmacokinetics, pharmacodynamics, tolerability and safety of doses of $0.1,0.3,1$, 3,5 or $10 \mathrm{mg} / \mathrm{kg}$ sub-cutaneus and 1 or $10 \mathrm{mg} / \mathrm{kg}$ intravenous of AMG 785. A total of 72 subjects participated in the study and were followed for up to 85 days. Study product pharmacokinetics was nonlinear with dose. Dose-related increases in bone formation markers and decreases in bone resorption markers were observed. A small percentage of the patients developed anti-investigational product bodies but most of them were nonneutralizing antibodies. The medication was well tolerated. (Padhi et al., 2011) A phase II study of 419 postmenopausal women with low BMD has been started to compare the efficacy of sclerostin neutralization with alendronate and teriparatide. (Rachner et al., 2011) Finally, a multicenter, phase IIa, randomized double-blind, placebo controlled, multi-dose study is ongoing to evaluate safety, tolerability, pharmacokinetics, and phamacodynamics of AMG 785 in postmenopausal women with low bone mass. In conclusion, anti sclerostin antibody treatment could be the most effective treatment for osteoporosis and bone defect related diseases. Even though, we will have to wait until all the ongoing and planned trials are over to analyze the data and have access to this kind of treatment.

\section{Conclusion}

During the last 10 years, new therapeutic agents have emerged among the pharmacological treatment options for osteoporosis. The newer options belong to new families with optimized mechanisms of action, allowing us to restore the lost bone mass quicker and more effectively than with the old medications. Nevertheless, one has to be conscious that all treatment options have specific indications and a wide range of adverse events, that have to be taken into consideration before making any decision. Moreover, it has to be remembered that most treatments for osteoporosis have to be given concomitantly with changes in lifestyle and/or calcium and vitamin D supplementation. New therapies are in development that probably will allow us to treat for a shorter time obtaining better results for our patients. 


\section{References}

Bazedoxifene: bazedoxifene acetate, TSE 424, TSE-424, WAY 140424. 2008. Drugs in R\&D, 9(3), pp. 191-196.

Adomaityte, J., Farooq, M. and Qayyum, R., 2008. Effect of raloxifene therapy on venous thromboembolism in postmenopausal women. A meta-analysis. Thrombosis and haemostasis, 99(2), pp. 338-342.

Anderson, D.M., Maraskovsky, E., Billingsley, W.L., Dougall, W.C., Tometsko, M.E., Roux, E.R., Teepe, M.C., Dubose, R.F., Cosman, D. and Galibert, L., 1997. A homologue of the TNF receptor and its ligand enhance T-cell growth and dendritic-cell function. Nature, 390(6656), pp. 175-179.

Anderson, G.L., Judd, H.L., Kaunitz, A.M., Barad, D.H., Beresford, S.A., Pettinger, M., Liu, J., Mcneeley, S.G., Lopez, A.M. and Women's Health Initiative Investigators, 2003. Effects of estrogen plus progestin on gynecologic cancers and associated diagnostic procedures: the Women's Health Initiative randomized trial. JAMA : the journal of the American Medical Association, 290(13), pp. 1739-1748.

Anderson, G.L., Limacher, M., Assaf, A.R., Bassford, T., Beresford, S.A., Black, H., Bonds, D., Brunner, R., Brzyski, R., Caan, B., Chlebowski, R., Curb, D., Gass, M., Hays, J., Heiss, G., Hendrix, S., Howard, B.V., Hsia, J., Hubbell, A., Jackson, R., Johnson, K.C., Judd, H., Kotchen, J.M., Kuller, L., Lacroix, A.Z., Lane, D., Langer, R.D., Lasser, N., Lewis, C.E., Manson, J., Margolis, K., Ockene, J., O'sullivan, M.J., Phillips, L., Prentice, R.L., Ritenbaugh, C., Robbins, J., Rossouw, J.E., Sarto, G., Stefanick, M.L., Van Horn, L., Wactawski-Wende, J., Wallace, R., WassertheilSmoller, S. and Women's Health Initiative Steering Committee, 2004. Effects of conjugated equine estrogen in postmenopausal women with hysterectomy: the Women's Health Initiative randomized controlled trial. JAMA : the journal of the American Medical Association, 291(14), pp. 1701-1712.

Archer, D.F., Pinkerton, J.V., Utian, W.H., Menegoci, J.C., De Villiers, T.J., Yuen, C.K., Levine, A.B., Chines, A.A. and Constantine, G.D., 2009. Bazedoxifene, a selective estrogen receptor modulator: effects on the endometrium, ovaries, and breast from a randomized controlled trial in osteoporotic postmenopausal women. Menopause (New York, N.Y.), 16(6), pp. 1109-1115.

Ardissino, G., Schmitt, C.P., Bianchi, M.L., Dacco, V., Claris-Appiani, A. And Mehls, O., 2000. No difference in intestinal strontium absorption after oral or IV calcitriol in children with secondary hyperparathyroidism. The European Study Group on Vitamin D in Children with Renal Failure. Kidney international, 58(3), pp. 981-988.

Arlot, M.E., Jiang, Y., Genant, H.K., Zhao, J., Burt-Pichat, B., Roux, J.P., Delmas, P.D. and Meunier, P.J., 2008. Histomorphometric and microCT analysis of bone biopsies from postmenopausal osteoporotic women treated with strontium ranelate. Journal of bone and mineral research : the official journal of the American Society for Bone and Mineral Research, 23(2), pp. 215-222.

Balemans, W., Ebeling, M., Patel, N., Van Hul, E., Olson, P., Dioszegi, M., Lacza, C., Wuyts, W., Van Den Ende, J., Willems, P., Paes-Alves, A.F., Hill, S., Bueno, M., Ramos, F.J., Tacconi, P., Dikkers, F.G., Stratakis, C., Lindpaintner, K., Vickery, B., Foernzler, D. and Van Hul, W., 2001. Increased bone density in sclerosteosis is due to the deficiency of a novel secreted protein (SOST). Human molecular genetics, 10(5), pp. 537-543. 
Barnard, A.H., Hamersma, H., Kretzmar, J.H. and Beighton, P., 1980. Sclerosteosis in old age. South African medical journal = Suid-Afrikaanse tydskrif vir geneeskunde, 58(10), pp. 401-403.

Baron, R. and Rawadi, G., 2007. Targeting the Wnt/beta-catenin pathway to regulate bone formation in the adult skeleton. Endocrinology, 148(6), pp. 2635-2643.

Barrett-Connor, E., 1992. Risks and benefits of replacement estrogen. Annual Review of Medicine, 43, pp. 239-251.

Barrett-Connor, E., Mosca, L., Collins, P., Geiger, M.J., Grady, D., Kornitzer, M., Mcnabb, M.A., Wenger, N.K. and Raloxifene Use For The Heart (Ruth) Trial Investigators, 2006. Effects of raloxifene on cardiovascular events and breast cancer in postmenopausal women. The New England journal of medicine, 355(2), pp. 125137.

Bauer, D.C., Black, D.M., Garnero, P., Hochberg, M., Ott, S., Orloff, J., Thompson, D.E., Ewing, S.K., Delmas, P.D. and Fracture Intervention Trial Study Group, 2004. Change in bone turnover and hip, non-spine, and vertebral fracture in alendronatetreated women: the fracture intervention trial. Journal of bone and mineral research : the official journal of the American Society for Bone and Mineral Research, 19(8), pp. 1250-1258.

Beighton, P., 1988. Sclerosteosis. Journal of medical genetics, 25(3), pp. 200-203.

Biskobing, D.M., 2007. Update on bazedoxifene: a novel selective estrogen receptor modulator. Clinical interventions in aging, 2(3), pp. 299-303.

Black, D.M., Cummings, S.R., Karpf, D.B., Cauley, J.A., Thompson, D.E., Nevitt, M.C., Bauer, D.C., Genant, H.K., Haskell, W.L., Marcus, R., Ott, S.M., Torner, J.C., Quandt, S.A., Reiss, T.F. and Ensrud, K.E., 1996. Randomised trial of effect of alendronate on risk of fracture in women with existing vertebral fractures. Fracture Intervention Trial Research Group. Lancet, 348(9041), Pp. 1535-1541.

Black, D.M., Delmas, P.D., Eastell, R., Reid, I.R., Boonen, S., Cauley, J.A., Cosman, F., Lakatos, P., Leung, P.C., Man, Z., Mautalen, C., Mesenbrink, P., Hu, H., Caminis, J., Tong, K., Rosario-Jansen, T., Krasnow, J., Hue, T.F., Sellmeyer, D., Eriksen, E.F., Cummings, S.R. and Horizon Pivotal Fracture Trial, 2007. Once-yearly zoledronic acid for treatment of postmenopausal osteoporosis. The New England journal of medicine, 356(18), pp. 1809-1822.

Black, D.M., Greenspan, S.L., Ensrud, K.E., Palermo, L., Mcgowan, J.A., Lang, T.F., Garnero, P., Bouxsein, M.L., Bilezikian, J.P., Rosen, C.J. and Path Study Investigators, 2003. The effects of parathyroid hormone and alendronate alone or in combination in postmenopausal osteoporosis. The New England journal of medicine, 349(13), pp. 1207-1215.

Blake, G.M. and Fogelman, I., 2006a. Strontium ranelate: a novel treatment for postmenopausal osteoporosis: a review of safety and efficacy. Clinical interventions in aging, 1(4), pp. 367-375.

Blake, G.M. and Fogelman, I., 2006b. Theoretical model for the interpretation of BMD scans in patients stopping strontium ranelate treatment. Journal of bone and mineral research : the official journal of the American Society for Bone and Mineral Research, 21(9), pp. 1417-1424. 
Blake, G.M. and Fogelman, I., 2005. Long-term effect of strontium ranelate treatment on BMD. Journal of bone and mineral research : the official journal of the American Society for Bone and Mineral Research, 20(11), pp. 1901-1904.

Bone, H.G., Bolognese, M.A., Yuen, C.K., Kendler, D.L., Wang, H., Liu, Y. and San Martin, J., 2008. Effects of denosumab on bone mineral density and bone turnover in postmenopausal women. The Journal of clinical endocrinology and metabolism, 93(6), pp. 2149-2157.

Bonnelye, E., Chabadel, A., Saltel, F. and Jurdic, P., 2008. Dual effect of strontium ranelate: stimulation of osteoblast differentiation and inhibition of osteoclast formation and resorption in vitro. Bone, 42(1), pp. 129-138.

Bromme, D. and Lecaille, F., 2009. Cathepsin K inhibitors for osteoporosis and potential offtarget effects. Expert opinion on investigational drugs, 18(5), pp. 585-600.

Brown, E.,M., 2003. Is the calcium receptor a molecular target for the actions of strontium on bone? Osteoporosis International, (0), pp. 25-34.

Brown, J.P., Prince, R.L., Deal, C., Recker, R.R., Kiel, D.P., De Gregorio, L.H., Hadji, P., Hofbauer, L.C., Alvaro-Gracia, J.M., Wang, H., Austin, M., Wagman, R.B., Newmark, R., Libanati, C., San Martin, J. and Bone, H.G., 2009. Comparison of the Effect of Denosumab and Alendronate on Bone Mineral Density and Biochemical Markers of Bone Turnover in Postmenopausal Women With Low Bone Mass: A Randomized, Blinded, Phase 3 Trial. Journal of bone and mineral research : the official journal of the American Society for Bone and Mineral Research, , pp. 1-34.

Brunkow, M.E., Gardner, J.C., Van Ness, J., Paeper, B.W., Kovacevich, B.R., Proll, S., Skonier, J.E., Zhao, L., Sabo, P.J., Fu, Y., Alisch, R.S., Gillett, L., Colbert, T., Tacconi, P., Galas, D., Hamersma, H., Beighton, P. and Mulligan, J., 2001. Bone dysplasia sclerosteosis results from loss of the SOST gene product, a novel cystine knotcontaining protein. American Journal of Human Genetics, 68(3), pp. 577-589.

Burgess, T.L., Qian, Y., Kaufman, S., Ring, B.D., Van, G., Capparelli, C., Kelley, M., Hsu, H., Boyle, W.J., Dunstan, C.R., Hu, S. and Lacey, D.L., 1999. The ligand for osteoprotegerin (OPGL) directly activates mature osteoclasts. The Journal of cell biology, 145(3), pp. 527-538.

Burshell, A.L., Song, J., Dowsett, S.A., Mershon, J.L., Delmas, P.D., Secrest, R.J. and Cauley, J.A., 2008. Relationship between bone mass, invasive breast cancer incidence and raloxifene therapy in postmenopausal women with low bone mass or osteoporosis. Current medical research and opinion, 24(3), pp. 807-813.

Cabrera, W.E., Schrooten, I., De Broe, M.E. and D'haese, P.C., 1999. Strontium and bone. J Bone Miner Res, 14(5), pp. 661-8.

Carstens, J.H.Jr and Feinblatt, J.D., 1991. Future horizons for calcitonin: a U.S. perspective. Calcified tissue international, 49 Suppl 2, pp. S2-6.

Cauley, J.A., Black, D.M., Barrett-Connor, E., Harris, F., Shields, K., Applegate, W. and Cummings, S.R., 2001. Effects of hormone replacement therapy on clinical fractures and height loss: The Heart and Estrogen/Progestin Replacement Study (HERS). The American Journal of Medicine, 110(6), pp. 442-450.

Cauley, J.A., Robbins, J., Chen, Z., Cummings, S.R., Jackson, R.D., Lacroix, A.Z., Leboff, M., Lewis, C.E., Mcgowan, J., Neuner, J., Pettinger, M., Stefanick, M.L., WactawskiWende, J., Watts, N.B. and Women's Health Initiative Investigators, 2003. Effects of estrogen plus progestin on risk of fracture and bone mineral density: the Women's 
Health Initiative randomized trial. JAMA : the journal of the American Medical Association, 290(13), pp. 1729-1738.

Caverzasio, J., 2008. Strontium ranelate promotes osteoblastic cell replication through at least two different mechanisms. Bone, 42(6), pp. 1131-1136.

Chandrasekaran, A., Mckeand, W.E., Sullivan, P., Demaio, W., Stoltz, R. and Scatina, J., 2009. Metabolic disposition of [14C]bazedoxifene in healthy postmenopausal women. Drug metabolism and disposition: the biological fate of chemicals, 37(6), pp. 12191225.

Chapurlat, R. and Delmas, P.D., 2004. New treatments in osteoporosis. La Revue de medecine interne / fondee ...par la Societe nationale francaise de medecine interne, $25 \mathrm{Suppl}$ 5, pp. S573-9.

Chapurlat, R.D., Palermo, L., Ramsay, P. and Cummings, S.R., 2005. Risk of fracture among women who lose bone density during treatment with alendronate. The Fracture Intervention Trial. Osteoporosis international : a journal established as result of cooperation between the European Foundation for Osteoporosis and the National Osteoporosis Foundation of the USA, 16(7), pp. 842-848.

Cherry, N., Gilmour, K., Hannaford, P., Heagerty, A., Khan, M.A., Kitchener, H., Mcnamee, R., Elstein, M., Kay, C., Seif, M., Buckley, H. and Esprit Team, 2002. Oestrogen therapy for prevention of reinfarction in postmenopausal women: a randomised placebo controlled trial. Lancet, 360(9350), pp. 2001-2008.

Chesnut, C.H., 2006. Treating osteoporosis with bisphosphonates and addressing adherence: a review of oral ibandronate. Drugs, 66(10), pp. 1351-1359.

Chesnut, C.H.,3rd, Silverman, S., Andriano, K., Genant, H., Gimona, A., Harris, S., Kiel, D., Leboff, M., Maricic, M., Miller, P., Moniz, C., Peacock, M., Richardson, P., Watts, N. and Baylink, D., 2000. A randomized trial of nasal spray salmon calcitonin in postmenopausal women with established osteoporosis: the prevent recurrence of osteoporotic fractures study. PROOF Study Group. The American Journal of Medicine, 109(4), pp. 267-276.

Chlebowski, R.T., Hendrix, S.L., Langer, R.D., Stefanick, M.L., Gass, M., Lane, D., Rodabough, R.J., Gilligan, M.A., Cyr, M.G., Thomson, C.A., Khandekar, J., Petrovitch, H., Mctiernan, A. And Whi Investigators, 2003. Influence of estrogen plus progestin on breast cancer and mammography in healthy postmenopausal women: the Women's Health Initiative Randomized Trial. JAMA : the journal of the American Medical Association, 289(24), pp. 3243-3253.

Clarke, B.L. and Khosla, S., 2009. New selective estrogen and androgen receptor modulators. Current opinion in rheumatology, 21(4), pp. 374-379.

Close, P., Neuprez, A. and Reginster, J.Y., 2006. Developments in the pharmacotherapeutic management of osteoporosis. Expert Opin Pharmacother, 7(12), pp. 1603-15.

Collins, P., Mosca, L., Geiger, M.J., Grady, D., Kornitzer, M., Amewou-Atisso, M.G., Effron, M.B., Dowsett, S.A., Barrett-Connor, E. and Wenger, N.K., 2009. Effects of the selective estrogen receptor modulator raloxifene on coronary outcomes in the Raloxifene Use for The Heart trial: results of subgroup analyses by age and other factors. Circulation, 119(7), pp. 922-930.

Coughlin, S.S., Giustozzi, A., Smith, S.J. and Lee, N.C., 2000. A meta-analysis of estrogen replacement therapy and risk of epithelial ovarian cancer. Journal of clinical epidemiology, 53(4), pp. 367-375. 
Cranney, A., Tugwell, P., Zytaruk, N., Robinson, V., Weaver, B., Adachi, J., Wells, G., Shea, B., Guyatt, G. And Osteoporosis Methodology Group and The Osteoporosis Research Advisory Group, 2002. Meta-analyses of therapies for postmenopausal osteoporosis. IV. Meta-analysis of raloxifene for the prevention and treatment of postmenopausal osteoporosis. Endocrine reviews, 23(4), pp. 524-528.

Cummings, S.R., San Martin, J., Mcclung, M.R., Siris, E.S., Eastell, R., Reid, I.R., Delmas, P., Zoog, H.B., Austin, M., Wang, A., Kutilek, S., Adami, S., Zanchetta, J., Libanati, C., Siddhanti, S., Christiansen, C. and Freedom Trial, 2009. Denosumab for prevention of fractures in postmenopausal women with osteoporosis. The New England journal of medicine, 361(8), pp. 756-765.

Delmas, P.D., Bjarnason, N.H., Mitlak, B.H., Ravoux, A.C., Shah, A.S., Huster, W.J., Draper, M. and Christiansen, C., 1997. Effects of raloxifene on bone mineral density, serum cholesterol concentrations, and uterine endometrium in postmenopausal women. The New England journal of medicine, 337(23), pp. 1641-1647.

Delmas, P.D., Recker, R.R., Chesnut, C.H.,3rd, Skag, A., Stakkestad, J.A., Emkey, R., Gilbride, J., Schimmer, R.C. and Christiansen, C., 2004. Daily and intermittent oral ibandronate normalize bone turnover and provide significant reduction in vertebral fracture risk: results from the BONE study. Osteoporosis international : a journal established as result of cooperation between the European Foundation for Osteoporosis and the National Osteoporosis Foundation of the USA, 15(10), pp. 792-798.

Delmas, P.D., Vrijens, B., Eastell, R., Roux, C., Pols, H.A., Ringe, J.D., Grauer, A., Cahall, D., Watts, N.B. and Improving Measurements Of Persistence On Actonel Treatment (Impact) Investigators, 2007. Effect of monitoring bone turnover markers on persistence with risedronate treatment of postmenopausal osteoporosis. The Journal of clinical endocrinology and metabolism, 92(4), pp. 1296-1304.

Dempster, D.W., Cosman, F., Kurland, E.S., Zhou, H., Nieves, J., Woelfert, L., Shane, E., Plavetic, K., Muller, R., Bilezikian, J. and Lindsay, R., 2001. Effects of daily treatment with parathyroid hormone on bone microarchitecture and turnover in patients with osteoporosis: a paired biopsy study. Journal of bone and mineral research: the official journal of the American Society for Bone and Mineral Research, 16(10), pp. 1846-1853.

Eastell, R., Nagase, S., Ohyama, M., Small, M., Sawyer, J., Boonen, S., Spector, T., Kuwayama, T. and Deacon, S., 2011. Safety and efficacy of the cathepsin K inhibitor ONO-5334 in postmenopausal osteoporosis: the OCEAN study. Journal of bone and mineral research : the official journal of the American Society for Bone and Mineral Research, 26(6), pp. 1303-1312.

Eghbali-Fatourechi, G., Khosla, S., Sanyal, A., Boyle, W.J., Lacey, D.L. and Riggs, B.L., 2003. Role of RANK ligand in mediating increased bone resorption in early postmenopausal women. The Journal of clinical investigation, 111(8), pp. 12211230.

Ekstrand, J. and Spak, C.J., 1990. Fluoride pharmacokinetics: its implications in the fluoride treatment of osteoporosis. Journal of bone and mineral research : the official journal of the American Society for Bone and Mineral Research, 5 Suppl 1, pp. S53-61.

Ensrud, K.E., Black, D.M., Palermo, L., Bauer, D.C., Barrett-Connor, E., Quandt, S.A., Thompson, D.E. and Karpf, D.B., 1997. Treatment with alendronate prevents 
fractures in women at highest risk: results from the Fracture Intervention Trial. Archives of Internal Medicine, 157(22), pp. 2617-2624.

Ermer, J., Mckeand, W., Sullivan, P., Parker, V. and Orczyk, G., 2003. Bazedoxifene Acetate Dose Proportionality in Healthy, Postmenopausal Women. Clinical pharmacology and therapeutics, 73(2), pp. P46-P46.

Ettinger, B., San Martin, J., Crans, G. and Pavo, I., 2004. Differential effects of teriparatide on BMD after treatment with raloxifene or alendronate. Journal of bone and mineral research : the official journal of the American Society for Bone and Mineral Research, 19(5), pp. 745-751.

Farrerons, J., Rodriguez De La Serna, A., Guanabens, N., Armadans, L., Lopez-Navidad, A., Yoldi, B., Renau, A. and Vaque, J., 1997. Sodium fluoride treatment is a major protector against vertebral and nonvertebral fractures when compared with other common treatments of osteoporosis: a longitudinal, observational study. Calcified tissue international, 60(3), pp. 250-254.

Finkelstein, J.S., Hayes, A., Hunzelman, J.L., Wyland, J.J., Lee, H. and Neer, R.M., 2003. The effects of parathyroid hormone, alendronate, or both in men with osteoporosis. The New England journal of medicine, 349(13), pp. 1216-1226.

Fleurence, R.L., Iglesias, C.P. and Johnson, J.M., 2007. The cost effectiveness of bisphosphonates for the prevention and treatment of osteoporosis: a structured review of the literature. PharmacoEconomics, 25(11), pp. 913-933.

Garg, P.P., Kerlikowske, K., Subak, L. and Grady, D., 1998. Hormone Replacement Therapy and the Risk of Epithelial Ovarian Carcinoma: A Meta-Analysis. Obstetrics \& Gynecology, 92(3),

Gennari, L., Merlotti, D., De Paola, V. and Nuti, R., 2010. Lasofoxifene: Evidence of its therapeutic value in osteoporosis. Core evidence, 4, pp. 113-129.

Giammarile, F., Mognetti, T., Blondet, C., Desuzinges, C. and Chauvot, P., 1999. Bone pain palliation with $85 \mathrm{Sr}$ therapy. Journal of nuclear medicine : official publication, Society of Nuclear Medicine, 40(4), pp. 585-590.

Grady, D., Gebretsadik, T., Kerlikowske, K., Ernster, V. and Petitti, D., 1995. Hormone replacement therapy and endometrial cancer risk: a meta-analysis. Obstetrics and gynecology, 85(2), pp. 304-313.

Grady, D., Herrington, D., Bittner, V., Blumenthal, R., Davidson, M., Hlatky, M., Hsia, J., Hulley, S., Herd, A., Khan, S., Newby, L.K., Waters, D., Vittinghoff, E., Wenger, N. and Hers Research Group, 2002. Cardiovascular disease outcomes during 6.8 years of hormone therapy: Heart and Estrogen/progestin Replacement Study follow-up (HERS II). JAMA : the journal of the American Medical Association, 288(1), pp. 4957.

Greenspan, S.L., Bone, H.G., Ettinger, M.P., Hanley, D.A., Lindsay, R., Zanchetta, J.R., Blosch, C.M., Mathisen, A.L., Morris, S.A., Marriott, T.B. and Treatment Of Osteoporosis With Parathyroid Hormone Study Group, 2007. Effect of recombinant human parathyroid hormone (1-84) on vertebral fracture and bone mineral density in postmenopausal women with osteoporosis: a randomized trial. Annals of Internal Medicine, 146(5), pp. 326-339.

Gruber, C. and Gruber, D., 2004. Bazedoxifene (Wyeth). Current opinion in investigational drugs (London, England : 2000), 5(10), pp. 1086-1093. 
Grupo De Trabajo De Menopausia y Postmenopausia., 2004. Guía de práctica clínica sobre la menopausia y postmenopausia. Barcelona: Sociedad Española de Ginecología y Obstetricia, Asociación Española para el Estudio de la Menopausia, Sociedad Española de Medicina de Familia y Comunitaria y Centro Cochrane Iberoamericano.

Haguenauer, D., Welch, V., Shea, B., Tugwell, P., Adachi, J.D. and Wells, G., 2000a. Fluoride for the treatment of postmenopausal osteoporotic fractures: a meta-analysis. Osteoporosis international : a journal established as result of cooperation between the European Foundation for Osteoporosis and the National Osteoporosis Foundation of the USA, 11(9), pp. 727-738.

Haguenauer, D., Welch, V., Shea, B., Tugwell, P. and Wells, G., 2000b. Fluoride for treating postmenopausal osteoporosis. Cochrane database of systematic reviews (Online), (4)(4), pp. CD002825.

Halil, M., Cankurtaran, M., Yavuz, B.B., Ulger, Z., Piskinpasa, S., Gedik, A., Haznedaroglu, I.C., Kirazli, S. and Ariogul, S., 2007. Short-term hemostatic safety of strontium ranelate treatment in elderly women with osteoporosis. The Annals of Pharmacotherapy, 41(1), pp. 41-45.

Hamersma, H., Gardner, J. and Beighton, P., 2003. The natural history of sclerosteosis. Clinical genetics, 63(3), pp. 192-197.

Heaney, R.P., 1994. Fluoride and Osteoporosis. Annals of Internal Medicine, 120(8), pp. 689690.

Henrotin, Y., Labasse, A., Zheng, S.X., Galais, P., Tsouderos, Y., Crielaard, J.M. and Reginster, J.Y., 2001. Strontium ranelate increases cartilage matrix formation. J Bone Miner Res, 16(2), pp. 299-308.

Herrington, D.M., Reboussin, D.M., Brosnihan, K.B., Sharp, P.C., Shumaker, S.A., Snyder, T.E., Furberg, C.D., Kowalchuk, G.J., Stuckey, T.D., Rogers, W.J., Givens, D.H. and Waters, D., 2000. Effects of estrogen replacement on the progression of coronaryartery atherosclerosis. The New England journal of medicine, 343(8), pp. 522-529.

Hiligsmann, M. and Reginster, J.Y., 2011. Cost Effectiveness of Denosumab Compared with Oral Bisphosphonates in the Treatment of Post-Menopausal Osteoporotic Women in Belgium. PharmacoEconomics, .

Hodsman, A.B., Bauer, D.C., Dempster, D.W., Dian, L., Hanley, D.A., Harris, S.T., Kendler, D.L., Mcclung, M.R., Miller, P.D., Olszynski, W.P., Orwoll, E. and Yuen, C.K., 2005. Parathyroid hormone and teriparatide for the treatment of osteoporosis: a review of the evidence and suggested guidelines for its use. Endocrine reviews, 26(5), pp. 688-703.

Hodsman, A.B., Hanley, D.A., Ettinger, M.P., Bolognese, M.A., Fox, J., Metcalfe, A.J. and Lindsay, R., 2003. Efficacy and safety of human parathyroid hormone-(1-84) in increasing bone mineral density in postmenopausal osteoporosis. The Journal of clinical endocrinology and metabolism, 88(11), pp. 5212-5220.

Hulley, S., Furberg, C., Barrett-Connor, E., Cauley, J., Grady, D., Haskell, W., Knopp, R., Lowery, M., Satterfield, S., Schrott, H., Vittinghoff, E., Hunninghake, D. and Hers Research Group, 2002. Noncardiovascular disease outcomes during 6.8 years of hormone therapy: Heart and Estrogen/progestin Replacement Study follow-up (HERS II). JAMA : the journal of the American Medical Association, 288(1), pp. 5866. 
Hulley, S., Grady, D., Bush, T., Furberg, C., Herrington, D., Riggs, B. and Vittinghoff, E., 1998. Randomized trial of estrogen plus progestin for secondary prevention of coronary heart disease in postmenopausal women. Heart and Estrogen/progestin Replacement Study (HERS) Research Group. JAMA : the journal of the American Medical Association, 280(7), pp. 605-613.

Humphrey, L.L., Chan, B.K. and Sox, H.C., 2002. Postmenopausal hormone replacement therapy and the primary prevention of cardiovascular disease. Annals of Internal Medicine, 137(4), pp. 273-284.

Johnell, O., Scheele, W.H., Lu, Y., Reginster, J.Y., Need, A.G. and Seeman, E., 2002. Additive effects of raloxifene and alendronate on bone density and biochemical markers of bone remodeling in postmenopausal women with osteoporosis. The Journal of clinical endocrinology and metabolism, 87(3), pp. 985-992.

Johnston, C.C.Jr, Bjarnason, N.H., Cohen, F.J., Shah, A., Lindsay, R., Mitlak, B.H., Huster, W., Draper, M.W., Harper, K.D., Heath, H.,3rd, Gennari, C., Christiansen, C., Arnaud, C.D. and Delmas, P.D., 2000. Long-term effects of raloxifene on bone mineral density, bone turnover, and serum lipid levels in early postmenopausal women: three-year data from 2 double-blind, randomized, placebo-controlled trials. Archives of Internal Medicine, 160(22), pp. 3444-3450.

Jolly, E.E., Bjarnason, N.H., Neven, P., Plouffe, L.,Jr, Johnston, C.C.,Jr, Watts, S.D., Arnaud, C.D., Mason, T.M., Crans, G., Akers, R. and Draper, M.W., 2003. Prevention of osteoporosis and uterine effects in postmenopausal women taking raloxifene for 5 years. Menopause (New York, N.Y.), 10(4), pp. 337-344.

Jonsson, B., Strom, O., Eisman, J.A., Papaioannou, A., Siris, E.S., Tosteson, A. and Kanis, J.A., 2011. Cost-effectiveness of Denosumab for the treatment of postmenopausal osteoporosis. Osteoporosis international : a journal established as result of cooperation between the European Foundation for Osteoporosis and the National Osteoporosis Foundation of the USA, 22(3), pp. 967-982.

Kavanagh, K.L., Guo, K., Dunford, J.E., Wu, X., Knapp, S., Ebetino, F.H., Rogers, M.J., Russell, R.G. and Oppermann, U., 2006. The molecular mechanism of nitrogencontaining bisphosphonates as antiosteoporosis drugs. Proceedings of the National Academy of Sciences of the United States of America, 103(20), pp. 7829-7834.

Kearns, A.E., Khosla, S. and Kostenuik, P.J., 2008. Receptor activator of nuclear factor kappaB ligand and osteoprotegerin regulation of bone remodeling in health and disease. Endocrine reviews, 29(2), pp. 155-192.

Keaveny, T.M., Donley, D.W., Hoffmann, P.F., Mitlak, B.H., Glass, E.V. and San Martin, J.A., 2007. Effects of teriparatide and alendronate on vertebral strength as assessed by finite element modeling of QCT scans in women with osteoporosis. Journal of bone and mineral research : the official journal of the American Society for Bone and Mineral Research, 22(1), pp. 149-157.

Kendler, D.L., Roux, C., Benhamou, C.L., Brown, J.P., Lillestol, M., Siddhanti, S., Man, H.S., San Martin, J. and Bone, H.G., 2010. Effects of denosumab on bone mineral density and bone turnover in postmenopausal women transitioning from alendronate therapy. Journal of bone and mineral research : the official journal of the American Society for Bone and Mineral Research, 25(1), pp. 72-81.

Kharode, Y., Bodine, P.V., Miller, C.P., Lyttle, C.R. and Komm, B.S., 2008. The pairing of a selective estrogen receptor modulator, bazedoxifene, with conjugated estrogens as 
a new paradigm for the treatment of menopausal symptoms and osteoporosis prevention. Endocrinology, 149(12), pp. 6084-6091.

Komm, B.S., Kharode, Y.P., Bodine, P.V., Harris, H.A., Miller, C.P. and Lyttle, C.R., 2005. Bazedoxifene acetate: a selective estrogen receptor modulator with improved selectivity. Endocrinology, 146(9), pp. 3999-4008.

Komm, B.S. and Lyttle, C.R., 2001. Developing a SERM: stringent preclinical selection criteria leading to an acceptable candidate (WAY-140424) for clinical evaluation. Annals of the New York Academy of Sciences, 949, pp. 317-326.

Kong, Y.Y., Feige, U., Sarosi, I., Bolon, B., Tafuri, A., Morony, S., Capparelli, C., Li, J., Elliott, R., Mccabe, S., Wong, T., Campagnuolo, G., Moran, E., Bogoch, E.R., Van, G., Nguyen, L.T., Ohashi, P.S., Lacey, D.L., Fish, E., Boyle, W.J. And Penninger, J.M., 1999. Activated T Cells Regulate Bone Loss And Joint Destruction In adjuvant arthritis through osteoprotegerin ligand. Nature, 402(6759), pp. 304-309.

Kostenuik, P.J., Nguyen, H.Q., Mccabe, J., Warmington, K.S., Kurahara, C., Sun, N., Chen, C., Li, L., Cattley, R.C., Van, G., Scully, S., Elliott, R., Grisanti, M., Morony, S., Tan, H.L., Asuncion, F., Li, X., Ominsky, M.S., Stolina, M., Dwyer, D., Dougall, W.C., Hawkins, N., Boyle, W.J., Simonet, W.S. And Sullivan, J.K., 2009. Denosumab, a fully human monoclonal antibody to RANKL, inhibits bone resorption and increases BMD in knock-in mice that express chimeric (murine/human) RANKL. Journal of bone and mineral research : the official journal of the American Society for Bone and Mineral Research, 24(2), pp. 182-195.

Kulak Junior, J., Kulak, C.A. and Taylor, H.S., 2010. SERMs in the prevention and treatment of postmenopausal osteoporosis: an update. Arquivos Brasileiros de Endocrinologia e Metabologia, 54(2), pp. 200-205.

Lacey, D.L., Timms, E., Tan, H.L., Kelley, M.J., Dunstan, C.R., Burgess, T., Elliott, R., Colombero, A., Elliott, G., Scully, S., Hsu, H., Sullivan, J., Hawkins, N., Davy, E., Capparelli, C., Eli, A., Qian, Y.X., Kaufman, S., Sarosi, I., Shalhoub, V., Senaldi, G., Guo, J., Delaney, J. and Boyle, W.J., 1998. Osteoprotegerin ligand is a cytokine that regulates osteoclast differentiation and activation. Cell, 93(2), pp. 165-176.

Lacey, J.V.,Jr, Mink, P.J., Lubin, J.H., Sherman, M.E., Troisi, R., Hartge, P., Schatzkin, A. and Schairer, C., 2002. Menopausal hormone replacement therapy and risk of ovarian cancer. JAMA : the journal of the American Medical Association, 288(3), pp. 334341.

Leeuwenkamp, O.R., Van Der Vijgh, W.J., Husken, B.C., Lips, P. and Netelenbos, J.C., 1990. Human pharmacokinetics of orally administered strontium. Calcif Tissue Int, 47(3), pp. 136-41.

Leeuwenkamp, O.R., Van Der Vijgh, W.J., Husken, B.C., Lips, P. and Netelenbos, J.C., 1989. Quantification of strontium in plasma and urine with flameless atomic absorption spectrometry. Clin Chem, 35(9), pp. 1911-4.

Lethaby, A., Suckling, J., Barlow, D., Farquhar, C.M., Jepson, R.G. and Roberts, H., 2004. Hormone replacement therapy in postmenopausal women: endometrial hyperplasia and irregular bleeding. Cochrane database of systematic reviews (Online), (3)(3), pp. CD000402.

Levis, S., Quandt, S.A., Thompson, D., Scott, J., Schneider, D.L., Ross, P.D., Black, D., Suryawanshi, S., Hochberg, M., Yates, J. and Fit Research Group, 2002. Alendronate 
reduces the risk of multiple symptomatic fractures: results from the fracture intervention trial. Journal of the American Geriatrics Society, 50(3), pp. 409-415.

Levy, L.S., Martin, P.A. and Bidstrup, P.L., 1986. Investigation of the potential carcinogenicity of a range of chromium containing materials on rat lung. British journal of industrial medicine, 43(4), pp. 243-256.

Lewiecki, E.M., 2007a. Bazedoxifene and bazedoxifene combined with conjugated estrogens for the management of postmenopausal osteoporosis. Expert opinion on investigational drugs, 16(10), pp. 1663-1672.

Li, C.I., Malone, K.E., Porter, P.L., Weiss, N.S., Tang, M.T., Cushing-Haugen, K.L. and Daling, J.R., 2003. Relationship between long durations and different regimens of hormone therapy and risk of breast cancer. JAMA : the journal of the American Medical Association, 289(24), pp. 3254-3263.

Li, W.B., Hollriegl, V., Roth, P. and Oeh, U., 2006. Human biokinetics of strontium. Part I: intestinal absorption rate and its impact on the dose coefficient of $90 \mathrm{Sr}$ after ingestion. Radiation and environmental biophysics, 45(2), pp. 115-124.

Liberman, U.A., Hochberg, M.C., Geusens, P., Shah, A., Lin, J., Chattopadhyay, A. and Ross, P.D., 2006. Hip and non-spine fracture risk reductions differ among antiresorptive agents: Evidence from randomised controlled trials. International journal of clinical practice, 60(11), pp. 1394-1400.

Lindsay, R., 2011. Preventing osteoporosis with a tissue selective estrogen complex (TSEC) containing bazedoxifene/conjugated estrogens (BZA/CE). Osteoporosis international : a journal established as result of cooperation between the European Foundation for Osteoporosis and the National Osteoporosis Foundation of the USA, 22(2), pp. 447-451.

Lindsay, R., Scheele, W.H., Neer, R., Pohl, G., Adami, S., Mautalen, C., Reginster, J.Y., Stepan, J.J., Myers, S.L. and Mitlak, B.H., 2004. Sustained vertebral fracture risk reduction after withdrawal of teriparatide in postmenopausal women with osteoporosis. Archives of Internal Medicine, 164(18), pp. 2024-2030.

Liu, J.M., Wai-Chee Kung, A., Pheng, C.S., Zhu, H.M., Zhang, Z.L., Wu, Y.Y., Xu, L., Meng, X.W., Huang, M.L., Chung, L.P., Hussain, N.H., Sufian, S.S. and Chen, J.L., 2009. Efficacy and safety of $2 \mathrm{~g} /$ day of strontium ranelate in Asian women with postmenopausal osteoporosis. Bone, 45(3), pp. 460-465.

Lobo, R.A., Pinkerton, J.V., Gass, M.L., Dorin, M.H., Ronkin, S., Pickar, J.H. and Constantine, G., 2009. Evaluation of bazedoxifene/conjugated estrogens for the treatment of menopausal symptoms and effects on metabolic parameters and overall safety profile. Fertility and sterility, 92(3), pp. 1025-1038.

Lufkin, E.G., Wahner, H.W., O'fallon, W.M., Hodgson, S.F., Kotowicz, M.A., Lane, A.W., Judd, H.L., Caplan, R.H. and Riggs, B.L., 1992. Treatment of postmenopausal osteoporosis with transdermal estrogen. Annals of Internal Medicine, 117(1), pp. 19.

Lundy, M.W., Stauffer, M., Wergedal, J.E., Baylink, D.J., Featherstone, J.D., Hodgson, S.F. and Riggs, B.L., 1995. Histomorphometric analysis of iliac crest bone biopsies in placebo-treated versus fluoride-treated subjects. Osteoporosis international : a journal established as result of cooperation between the European Foundation for Osteoporosis and the National Osteoporosis Foundation of the USA, 5(2), pp. 115129. 
Lyles, K.W., Colon-Emeric, C.S., Magaziner, J.S., Adachi, J.D., Pieper, C.F., Mautalen, C., Hyldstrup, L., Recknor, C., Nordsletten, L., Moore, K.A., Lavecchia, C., Zhang, J., Mesenbrink, P., Hodgson, P.K., Abrams, K., Orloff, J.J., Horowitz, Z., Eriksen, E.F., Boonen, S. and Horizon Recurrent Fracture Trial, 2007. Zoledronic acid and clinical fractures and mortality after hip fracture. The New England journal of medicine, 357(18), pp. 1799-1809.

Lyritis, G.P., Tsakalakos, N., Magiasis, B., Karachalios, T., Yiatzides, A. and Tsekoura, M., 1991. Analgesic effect of salmon calcitonin in osteoporotic vertebral fractures: a double-blind placebo-controlled clinical study. Calcified tissue international, 49(6), pp. 369-372.

Maclean, C., Newberry, S., Maglione, M., Mcmahon, M., Ranganath, V., Suttorp, M., Mojica, W., Timmer, M., Alexander, A., Mcnamara, M., Desai, S.B., Zhou, A., Chen, S., Carter, J., Tringale, C., Valentine, D., Johnsen, B. and Grossman, J., 2008. Systematic review: comparative effectiveness of treatments to prevent fractures in men and women with low bone density or osteoporosis. Annals of Internal Medicine, 148(3), pp. 197-213.

Marie, P.J., 2003. Optimizing bone metabolism in osteoporosis: insight into the pharmacologic profile of strontium ranelate. Osteoporos Int, 14 Suppl 3, pp. S9-12.

Marie, P.J., De Vernejoul, M.C. and Lomri, A., 1992. Stimulation of bone formation in osteoporosis patients treated with fluoride associated with increased DNA synthesis by osteoblastic cells in vitro. Journal of bone and mineral research : the official journal of the American Society for Bone and Mineral Research, 7(1), pp. 103-113.

Martino, S., Disch, D., Dowsett, S.A., Keech, C.A. and Mershon, J.L., 2005. Safety assessment of raloxifene over eight years in a clinical trial setting. Current medical research and opinion, 21(9), pp. 1441-1452.

Marx, R.E., 2003. Pamidronate (Aredia) and zoledronate (Zometa) induced avascular necrosis of the jaws: a growing epidemic. Journal of oral and maxillofacial surgery : official journal of the American Association of Oral and Maxillofacial Surgeons, 61(9), pp. 1115-1117.

McCloskey, E., Selby, P., Davies, M., Robinson, J., Francis, R.M., Adams, J., Kayan, K., Beneton, M., Jalava, T., Pylkkanen, L., Kenraali, J., Aropuu, S. and Kanis, J.A., 2004. Clodronate reduces vertebral fracture risk in women with postmenopausal or secondary osteoporosis: results of a double-blind, placebo-controlled 3-year study. Journal of bone and mineral research : the official journal of the American Society for Bone and Mineral Research, 19(5), pp. 728-736.

Mcclung, M.R., Geusens, P., Miller, P.D., Zippel, H., Bensen, W.G., Roux, C., Adami, S., Fogelman, I., Diamond, T., Eastell, R., Meunier, P.J., Reginster, J.Y. and Hip Intervention Program Study Group, 2001. Effect of risedronate on the risk of hip fracture in elderly women. Hip Intervention Program Study Group. The New England journal of medicine, 344(5), pp. 333-340.

Mcclung, M.R., Siris, E., Cummings, S., Bolognese, M., Ettinger, M., Moffett, A., Emkey, R., Day, W., Somayaji, V. and Lee, A., 2006a. Prevention of bone loss in postmenopausal women treated with lasofoxifene compared with raloxifene. Menopause (New York, N.Y.), 13(3), pp. 377-386. 
Miller, J., Chan, B.K. and Nelson, H.D., 2002. Postmenopausal estrogen replacement and risk for venous thromboembolism: a systematic review and meta-analysis for the U.S. Preventive Services Task Force. Annals of Internal Medicine, 136(9), pp. 680-690.

Miller, P.D., Chines, A.A., Christiansen, C., Hoeck, H.C., Kendler, D.L., Lewiecki, E.M., Woodson, G., Levine, A.B., Constantine, G. and Delmas, P.D., 2008. Effects of bazedoxifene on BMD and bone turnover in postmenopausal women: 2-yr results of a randomized, double-blind, placebo-, and active-controlled study. Journal of bone and mineral research : the official journal of the American Society for Bone and Mineral Research, 23(4), pp. 525-535.

Mitwally, M.F., 2008. Bazedoxifene: a selective estrogen-receptor modulator. Women's health (London, England), 4(4), pp. 319-326.

Moro-Alvarez, M.J. and Diaz-Curiel, M., 2007. Pharmacological treatment of osteoporosis for people over 70. Aging clinical and experimental research, 19(3), pp. 246-254.

Mosekilde, L., Beck-Nielsen, H., Sorensen, O.H., Nielsen, S.P., Charles, P., Vestergaard, P., Hermann, A.P., Gram, J., Hansen, T.B., Abrahamsen, B., Ebbesen, E.N., Stilgren, L., Jensen, L.B., Brot, C., Hansen, B., Tofteng, C.L., Eiken, P. and Kolthoff, N., 2000. Hormonal replacement therapy reduces forearm fracture incidence in recent postmenopausal women - results of the Danish Osteoporosis Prevention Study. Maturitas, 36(3), pp. 181-193.

Musette, P., Brandi, M.L., Cacoub, P., Kaufman, J.M., Rizzoli, R. and Reginster, J.Y., 2010. Treatment of osteoporosis: recognizing and managing cutaneous adverse reactions and drug-induced hypersensitivity. Osteoporosis international : a journal established as result of cooperation between the European Foundation for Osteoporosis and the National Osteoporosis Foundation of the USA, 21(5), pp. 723732.

National Institute For Clinical Excellence (Nice), 2008. Systematic reviews of clinical effectiveness prepared for the guideline 'Osteoporosis: Assessment of fracture risk and the prevention of osteoporotic fractures in individuals at high risk', 2008, National Institute for Health and Clinical Excellence.

Neer, R.M., Arnaud, C.D., Zanchetta, J.R., Prince, R., Gaich, G.A., Reginster, J.Y., Hodsman, A.B., Eriksen, E.F., Ish-Shalom, S., Genant, H.K., Wang, O. and Mitlak, B.H., 2001. Effect of parathyroid hormone (1-34) on fractures and bone mineral density in postmenopausal women with osteoporosis. The New England journal of medicine, 344(19), pp. 1434-1441.

Negri, E., Tzonou, A., Beral, V., Lagiou, P., Trichopoulos, D., Parazzini, F., Franceschi, S., Booth, M. and La Vecchia, C., 1999. Hormonal therapy for menopause and ovarian cancer in a collaborative re-analysis of European studies. International journal of cancer.Journal international du cancer, 80(6), pp. 848-851.

Nelson, H.D., 2004. Commonly used types of postmenopausal estrogen for treatment of hot flashes: scientific review. JAMA : the journal of the American Medical Association, 291(13), pp. 1610-1620.

Obermayer-Pietsch, B.M., Marin, F., Mccloskey, E.V., Hadji, P., Farrerons, J., Boonen, S., Audran, M., Barker, C., Anastasilakis, A.D., Fraser, W.D., Nickelsen, T. and Eurofors Investigators, 2008. Effects of two years of daily teriparatide treatment on BMD in postmenopausal women with severe osteoporosis with and without prior 
antiresorptive treatment. Journal of bone and mineral research : the official journal of the American Society for Bone and Mineral Research, 23(10), pp. 1591-1600.

O'duffy, J.D., Wahner, H.W., O'fallon, W.M., Johnson, K.A., Muhs, J.M., Beabout, J.W., Hodgson, S.F. And Riggs, B.L., 1986. Mechanism of acute lower extremity pain syndrome in fluoride-treated osteoporotic patients. The American Journal of Medicine, 80(4), pp. 561-566.

Olmos-Martinez JM, Gonzalez-Macias J. Mecanismo de acción de los bisfosfonatos. Med Clin (Barc). 2008;9(7):22-7.

Orwoll, E.S., Scheele, W.H., Paul, S., Adami, S., Syversen, U., Diez-Perez, A., Kaufman, J.M., Clancy, A.D. and Gaich, G.A., 2003. The effect of teriparatide [human parathyroid hormone (1-34)] therapy on bone density in men with osteoporosis. Journal of bone and mineral research : the official journal of the American Society for Bone and Mineral Research, 18(1), pp. 9-17.

Ott, S.M., 2005. Sclerostin and Wnt signaling--the pathway to bone strength. The Journal of clinical endocrinology and metabolism, 90(12), pp. 6741-6743.

Overgaard, K., Agnusdei, D., Hansen, M.A., Maioli, E., Christiansen, C. and Gennari, C., 1991. Dose-response bioactivity and bioavailability of salmon calcitonin in premenopausal and postmenopausal women. The Journal of clinical endocrinology and metabolism, 72(2), pp. 344-349.

Overgaard, K., Hansen, M.A., Jensen, S.B. and Christiansen, C., 1992. Effect of salcatonin given intranasally on bone mass and fracture rates in established osteoporosis: a dose-response study. BMJ (Clinical research ed.), 305(6853), pp. 556-561.

Padhi, D., Jang, G., Stouch, B., Fang, L. and Posvar, E., 2011. Single-dose, placebo-controlled, randomized study of AMG 785, a sclerostin monoclonal antibody. Journal of bone and mineral research : the official journal of the American Society for Bone and Mineral Research, 26(1), pp. 19-26.

Pandey, J. and Pandey, U., 2011. Fluoride Contamination and Fluorosis in Rural Community in the Vicinity of a Phosphate Fertilizer Factory in India. Bulletin of environmental contamination and toxicology.

Papworth, D.G. and Patrick, G., 1970. The kinetics of influx of calcium and strontium into rat intestine in vitro. J Physiol, 210(4), pp. 999-1020.

Papworth, D.G. and Vennart, J., 1984. The uptake and turnover of 90Sr in the human skeleton. Phys Med Biol, 29(9), pp. 1045-61.

Patat, A., Mckeand, W., Baird-Bellaire, S., Ermer, J. and Lecoz, F., 2003. Absolute/Relative Bioavailability of Bazedoxifene Acetate in Healthy Postmenopausal Women. Clinical pharmacology and therapeutics, 73(2), pp. P43-P43.

Peano, B.J., Crabtree, J.S., Komm, B.S., Winneker, R.C. and Harris, H.A., 2009. Effects of various selective estrogen receptor modulators with or without conjugated estrogens on mouse mammary gland. Endocrinology, 150(4), pp. 1897-1903.

Perez-Edo L. La inhibición del RANKL en el tratamiento de la osteoporosis: denosumab. Semin Fund Esp Reumatol. 2011;12(1):27-30.

Peterson, G.M., Naunton, M., Tichelaar, L.K. and Gennari, L., 2011. Lasofoxifene: selective estrogen receptor modulator for the prevention and treatment of postmenopausal osteoporosis. The Annals of Pharmacotherapy, 45(4), pp. 499-509. 
Pickar, J.H., Yeh, I.T., Bachmann, G. and Speroff, L., 2009. Endometrial effects of a tissue selective estrogen complex containing bazedoxifene/conjugated estrogens as a menopausal therapy. Fertility and sterility, 92(3), pp. 1018-1024.

Pinkerton, J.V., Archer, D.F., Utian, W.H., Menegoci, J.C., Levine, A.B., Chines, A.A. and Constantine, G.D., 2009. Bazedoxifene effects on the reproductive tract in postmenopausal women at risk for osteoporosis. Menopause (New York, N.Y.), 16(6), pp. 1102-1108.

Poole, K.E., Van Bezooijen, R.L., Loveridge, N., Hamersma, H., Papapoulos, S.E., Lowik, C.W. and Reeve, J., 2005. Sclerostin is a delayed secreted product of osteocytes that inhibits bone formation. The FASEB journal : official publication of the Federation of American Societies for Experimental Biology, 19(13), pp. 1842-1844.

Quandt, S.A., Thompson, D.E., Schneider, D.L., Nevitt, M.C., Black, D.M. and Fracture Intervention Trial Research Group, 2005. Effect of alendronate on vertebral fracture risk in women with bone mineral density T scores of-1.6 to -2.5 at the femoral neck: the Fracture Intervention Trial. Mayo Clinic proceedings.Mayo Clinic, 80(3), pp. 343-349.

Rachner, T.D., Khosla, S. and Hofbauer, L.C., 2011. Osteoporosis: now and the future. Lancet, 377(9773), pp. 1276-1287.

Ravn, P., Bidstrup, M., Wasnich, R.D., Davis, J.W., Mcclung, M.R., Balske, A., Coupland, C., Sahota, O., Kaur, A., Daley, M. and Cizza, G., 1999. Alendronate and estrogenprogestin in the long-term prevention of bone loss: four-year results from the early postmenopausal intervention cohort study. A randomized, controlled trial. Annals of Internal Medicine, 131(12), pp. 935-942.

Recker, R.R., Bare, S.P., Smith, S.Y., Varela, A., Miller, M.A., Morris, S.A. and Fox, J., 2009. Cancellous and cortical bone architecture and turnover at the iliac crest of postmenopausal osteoporotic women treated with parathyroid hormone 1-84. Bone, 44(1), pp. 113-119.

Reginster, J.Y., Kaufman, J.M. and Goemaere, S., 2010. IOF Regionals $1^{\text {st }}$ Asia-Pacific Osteoporosis Meeting. Osteoporosis International, (0), pp. 663-674.

Reginster, J., Minne, H.W., Sorensen, O.H., Hooper, M., Roux, C., Brandi, M.L., Lund, B., Ethgen, D., Pack, S., Roumagnac, I. and Eastell, R., 2000. Randomized trial of the effects of risedronate on vertebral fractures in women with established postmenopausal osteoporosis. Vertebral Efficacy with Risedronate Therapy (VERT) Study Group. Osteoporosis international : a journal established as result of cooperation between the European Foundation for Osteoporosis and the National Osteoporosis Foundation of the USA, 11(1), pp. 83-91.

Reginster, J.Y., Deroisy, R. and Jupsin, I., 2003. Strontium ranelate: a new paradigm in the treatment of osteoporosis. Drugs Today (Barc), 39(2), pp. 89-101.

Reginster, J.Y., Felsenberg, D., Boonen, S., Diez-Perez, A., Rizzoli, R., Brandi, M.L., Spector, T.D., Brixen, K., Goemaere, S., Cormier, C., Balogh, A., Delmas, P.D. and Meunier, P.J., 2008. Effects of long-term strontium ranelate treatment on the risk of nonvertebral and vertebral fractures in postmenopausal osteoporosis: Results of a five-year, randomized, placebo-controlled trial. Arthritis and Rheumatism, 58(6), pp. 1687-1695.

Reginster, J.Y., Malaise, O., Neuprez, A. and Bruyere, O., 2007. Strontium ranelate in the prevention of osteoporotic fractures. Int J Clin Pract, 61(2), pp. 324-8. 
Reginster, J.Y. And Meunier, P.J., 2003. Strontium ranelate phase 2 dose-ranging studies: PREVOS and STRATOS studies. Osteoporos Int, 14 Suppl 3, pp. S56-65.

Reginster, J.Y., Meurmans, L., Zegels, B., Rovati, L.C., Minne, H.W., Giacovelli, G., Taquet, A.N., Setnikar, I., Collette, J. and Gosset, C., 1998. The effect of sodium monofluorophosphate plus calcium on vertebral fracture rate in postmenopausal women with moderate osteoporosis. A randomized, controlled trial. Annals of Internal Medicine, 129(1), pp. 1-8.

Reginster, J.Y., Seeman, E., De Vernejoul, M.C., Adami, S., Compston, J., Phenekos, C., Devogelaer, J.P., Curiel, M.D., Sawicki, A., Goemaere, S., Sorensen, O.H., Felsenberg, D. and Meunier, P.J., 2005. Strontium ranelate reduces the risk of nonvertebral fractures in postmenopausal women with osteoporosis: Treatment of Peripheral Osteoporosis (TROPOS) study. J Clin Endocrinol Metab, 90(5), pp. 281622.

Rodriguez, C., Patel, A.V., Calle, E.E., Jacob, E.J. and Thun, M.J., 2001. Estrogen replacement therapy and ovarian cancer mortality in a large prospective study of US women. JAMA : the journal of the American Medical Association, 285(11), pp. 1460-1465.

Ronkin, S., Northington, R., Baracat, E., Nunes, M.G., Archer, D.F., Constantine, G. and Pickar, J.H., 2005. Endometrial effects of bazedoxifene acetate, a novel selective estrogen receptor modulator, in postmenopausal women. Obstetrics and gynecology, 105(6), pp. 1397-1404.

Rosen, C.J. and Bilezikian, J.P., 2001. Clinical review 123: Anabolic therapy for osteoporosis. The Journal of clinical endocrinology and metabolism, 86(3), pp. 957-964.

Rossouw, J.E., Anderson, G.L., Prentice, R.L., Lacroix, A.Z., Kooperberg, C., Stefanick, M.L., Jackson, R.D., Beresford, S.A., Howard, B.V., Johnson, K.C., Kotchen, J.M., Ockene, J. and Writing Group For The Women's Health Initiative Investigators, 2002. Risks and benefits of estrogen plus progestin in healthy postmenopausal women: principal results From the Women's Health Initiative randomized controlled trial. JAMA : the journal of the American Medical Association, 288(3), pp. 321-333.

Saag, K.G., Zanchetta, J.R., Devogelaer, J.P., Adler, R.A., Eastell, R., See, K., Krege, J.H., Krohn, K. and Warner, M.R., 2009. Effects of teriparatide versus alendronate for treating glucocorticoid-induced osteoporosis: thirty-six-month results of a randomized, double-blind, controlled trial. Arthritis and Rheumatism, 60(11), pp. 3346-3355.

Saarto, T., Janes, R., Tenhunen, M. and Kouri, M., 2002. Palliative radiotherapy in the treatment of skeletal metastases. European journal of pain (London, England), 6(5), pp. 323-330.

Sacristan, J.A., Ortun, V., Rovira, J., Prieto, L., Garcia-Alonso, F. and Grupo Ecomed, 2004a. Economic assessment in medicine. Medicina clinica, 122(10), pp. 379-382.

Sacristan, J.A., Rovira, J., Ortun, V., Garcia-Alonso, F., Prieto, L., Antonanzas, F. and Grupo Ecomed, 2004b. Utilization of economic assessments of health interventions. Medicina clinica, 122(20), pp. 789-795.

Schilcher J, Michaëlsson K, Aspenberg P. Bisphosphonate use and atypical fractures of the femoral shaft. N Engl J Med. 2011 May 5;364(18):1728-37.

Seeman, E., Boonen, S., Borgstrom, F., Vellas, B., Aquino, J.P., Semler, J., Benhamou, C.L., Kaufman, J.M. and Reginster, J.Y., 2010. Five years treatment with strontium ranelate reduces vertebral and nonvertebral fractures and increases the number 
and quality of remaining life-years in women over 80 years of age. Bone, 46(4), pp. 1038-1042.

Seeman, E., Vellas, B., Benhamou, C., Aquino, J.P., Semler, J., Kaufman, J.M., Hoszowski, K., Varela, A.R., Fiore, C., Brixen, K., Reginster, J.Y. and Boonen, S., 2006. Strontium ranelate reduces the risk of vertebral and nonvertebral fractures in women eighty years of age and older. J Bone Miner Res, 21(7), pp. 1113-20.

Shane, E., Burr, D., Ebeling, P.R., Abrahamsen, B., Adler, R.A., Brown, T.D., Cheung, A.M., Cosman, F., Curtis, J.R., Dell, R., Dempster, D., Einhorn, T.A., Genant, H.K., Geusens, P., Klaushofer, K., Koval, K., Lane, J.M., Mckiernan, F., Mckinney, R., Ng, A., Nieves, J., O'keefe, R., Papapoulos, S., Sen, H.T., Van Der Meulen, M.C., Weinstein, R.S., Whyte, M. And American Society For Bone and Mineral Research, 2010. Atypical subtrochanteric and diaphyseal femoral fractures: report of a task force of the American Society for Bone and Mineral Research. Journal of bone and mineral research : the official journal of the American Society for Bone and Mineral Research, 25(11), pp. 2267-2294.

Shen, L., Ahmad, S., Park, S., Demaio, W., Oganesian, A., Hultin, T., Scatina, J., Bungay, P. and Chandrasekaran, A., 2010. In vitro metabolism, permeability, and efflux of bazedoxifene in humans. Drug metabolism and disposition: the biological fate of chemicals, 38(9), pp. 1471-1479.

Silverman, S.L., Christiansen, C., Genant, H.K., Vukicevic, S., Zanchetta, J.R., De Villiers, T.J., Constantine, G.D. and Chines, A.A., 2008. Efficacy of bazedoxifene in reducing new vertebral fracture risk in postmenopausal women with osteoporosis: results from a 3-year, randomized, placebo-, and active-controlled clinical trial. Journal of bone and mineral research : the official journal of the American Society for Bone and Mineral Research, 23(12), pp. 1923-1934.

Siris, E.S., Chen, Y.T., Abbott, T.A., Barrett-Connor, E., Miller, P.D., Wehren, L.E. and Berger, M.L., 2004. Bone mineral density thresholds for pharmacological intervention to prevent fractures. Archives of Internal Medicine, 164(10), pp. 1108-1112.

Stampfer, M.J., Colditz, G.A., Willett, W.C., Manson, J.E., Rosner, B., Speizer, F.E. and Hennekens, C.H., 1991. Postmenopausal estrogen therapy and cardiovascular disease. Ten-year follow-up from the nurses' health study. The New England journal of medicine, 325(11), pp. 756-762.

Stoch, S.A., Zajic, S., Stone, J., Miller, D.L., Van Dyck, K., Gutierrez, M.J., De Decker, M., Liu, L., Liu, Q., Scott, B.B., Panebianco, D., Jin, B., Duong, L.T., Gottesdiener, K. and Wagner, J.A., 2009. Effect of the cathepsin K inhibitor odanacatib on bone resorption biomarkers in healthy postmenopausal women: two double-blind, randomized, placebo-controlled phase I studies. Clinical pharmacology and therapeutics, 86(2), pp. 175-182.

Stovall, D.W. and Pinkerton, J.V., 2008. Estrogen agonists/antagonists in combination with estrogen for prevention and treatment of menopause-associated signs and symptoms. Women's health (London, England), 4(3), pp. 257-268.

Swan, V.J., Hamilton, C.J. and Jamal, S.A., 2010. Lasofoxifene in osteoporosis and its place in therapy. Advances in Therapy, 27(12), pp. 917-932.

Takahashi, N., Sasaki, T., Tsouderos, Y. and Suda, T., 2003. S 12911-2 inhibits osteoclastic bone resorption in vitro. Journal of bone and mineral research : the official journal of the American Society for Bone and Mineral Research, 18(6), pp. 1082-1087. 
Tashjian, A.H.Jr and Goltzman, D., 2008. On the interpretation of rat carcinogenicity studies for human PTH(1-34) and human PTH(1-84). Journal of bone and mineral research : the official journal of the American Society for Bone and Mineral Research, 23(6), pp. 803-811.

Turner, C.H., 1996. Fluoride and the FDA: a curious case. Journal of bone and mineral research : the official journal of the American Society for Bone and Mineral Research, 11(9), pp. 1369-1371.

Ulger, Z., Gurel, E.I., Halil, M., Oozen, G., Kalan, I., Seringec, N., Yavuz, B.B., Yesil, Y., Cankurtaran, M., Dikmenoglu, N. and Ariogul, S., 2010. Hemorheological changes with strontium ranelate treatment do not seem to be related to its claimed prothrombotic effects. Archives of Gerontology and Geriatrics.

Vahle, J.L., Long, G.G., Sandusky, G., Westmore, M., Ma, Y.L. and Sato, M., 2004. Bone neoplasms in F344 rats given teriparatide [rhPTH(1-34)] are dependent on duration of treatment and dose. Toxicologic pathology, 32(4), pp. 426-438.

Van Staa, T.P., Kanis, J.A., Geusens, P., Boonen, A., Leufkens, H.G. and Cooper, C., 2007. The cost-effectiveness of bisphosphonates in postmenopausal women based on individual long-term fracture risks. Value in health : the journal of the International Society for Pharmacoeconomics and Outcomes Research, 10(5), pp. 348-357.

Vestergaard, P., Jorgensen, N.R., Schwarz, P. and Mosekilde, L., 2008. Effects of treatment with fluoride on bone mineral density and fracture risk--a meta-analysis. Osteoporosis international : a journal established as result of cooperation between the European Foundation for Osteoporosis and the National Osteoporosis Foundation of the USA, 19(3), pp. 257-268.

Viscoli, C.M., Brass, L.M., Kernan, W.N., Sarrel, P.M., Suissa, S. and Horwitz, R.I., 2001. A clinical trial of estrogen-replacement therapy after ischemic stroke. The New England journal of medicine, 345(17), pp. 1243-1249.

Vogel, V.G., Costantino, J.P., Wickerham, D.L., Cronin, W.M., Cecchini, R.S., Atkins, J.N., Bevers, T.B., Fehrenbacher, L., Pajon, E.R.,Jr, Wade, J.L.,3rd, Robidoux, A., Margolese, R.G., James, J., Lippman, S.M., Runowicz, C.D., Ganz, P.A., Reis, S.E., Mccaskill-Stevens, W., Ford, L.G., Jordan, V.C., Wolmark, N. and National Surgical Adjuvant Breast And Bowel Project (Nsabp), 2006. Effects of tamoxifen vs raloxifene on the risk of developing invasive breast cancer and other disease outcomes: the NSABP Study of Tamoxifen and Raloxifene (STAR) P-2 trial. JAMA : the journal of the American Medical Association, 295(23), pp. 2727-2741.

Watts, N., 1999. Pharmacology og agents to treat osteoporosis. In: M. Favus, ed, Primer on the Metabolic Bone Diseases and Disorders of Mineral Metabolism. 4th edn. Philadelphia: Lippincott Williams \& Wilkins, pp. 278.

Wergedal, J.E., Veskovic, K., Hellan, M., Nyght, C., Balemans, W., Libanati, C., Vanhoenacker, F.M., Tan, J., Baylink, D.J. And Van Hul, W., 2003. Patients with Van Buchem disease, an osteosclerotic genetic disease, have elevated bone formation markers, higher bone density, and greater derived polar moment of inertia than normal. The Journal of clinical endocrinology and metabolism, 88(12), pp. 5778-5783.

Wimalawansa, S.J., 1998. A four-year randomized controlled trial of hormone replacement and bisphosphonate, alone or in combination, in women with postmenopausal osteoporosis. The American Journal of Medicine, 104(3), pp. 219-226. 
Yonemori, K., Fujiwara, Y., Minami, H., Kitagawa, K., Fujii, H., Arai, T., Sohn, W., Ohkura, M. and Ohtsu, T., 2008. Phase 1 trial of denosumab safety, pharmacokinetics, and pharmacodynamics in Japanese women with breast cancer-related bone metastases. Cancer science, 99(6), pp. 1237-1242. 


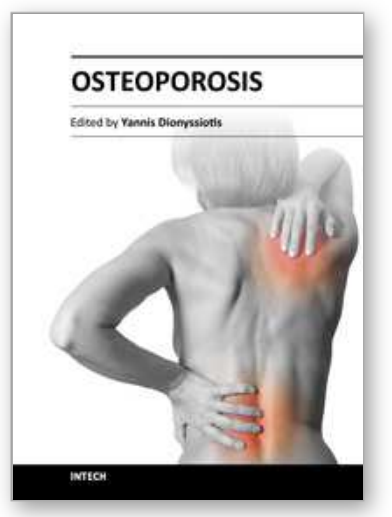

\author{
Osteoporosis \\ Edited by PhD. Yannis Dionyssiotis
}

ISBN 978-953-51-0026-3

Hard cover, 864 pages

Publisher InTech

Published online 24, February, 2012

Published in print edition February, 2012

Osteoporosis is a public health issue worldwide. During the last few years, progress has been made concerning the knowledge of the pathophysiological mechanism of the disease. Sophisticated technologies have added important information in bone mineral density measurements and, additionally, geometrical and mechanical properties of bone. New bone indices have been developed from biochemical and hormonal measurements in order to investigate bone metabolism. Although it is clear that drugs are an essential element of the therapy, beyond medication there are other interventions in the management of the disease. Prevention of osteoporosis starts in young ages and continues during aging in order to prevent fractures associated with impaired quality of life, physical decline, mortality, and high cost for the health system. A number of different specialties are holding the scientific knowledge in osteoporosis. For this reason, we have collected papers from scientific departments all over the world for this book. The book includes up-to-date information about basics of bones, epidemiological data, diagnosis and assessment of osteoporosis, secondary osteoporosis, pediatric issues, prevention and treatment strategies, and research papers from osteoporotic fields.

\title{
How to reference
}

In order to correctly reference this scholarly work, feel free to copy and paste the following:

Jorge Malouf-Sierra and Roberto Güerri-Fernández (2012). Pharmacological Treatment of Osteoporosis, Osteoporosis, PhD. Yannis Dionyssiotis (Ed.), ISBN: 978-953-51-0026-3, InTech, Available from: http://www.intechopen.com/books/osteoporosis/pharmacological-treatment-of-osteoporosis

\section{INTECH}

open science | open minds

\section{InTech Europe}

University Campus STeP Ri

Slavka Krautzeka 83/A

51000 Rijeka, Croatia

Phone: +385 (51) 770447

Fax: +385 (51) 686166

www.intechopen.com

\section{InTech China}

Unit 405, Office Block, Hotel Equatorial Shanghai

No.65, Yan An Road (West), Shanghai, 200040, China 中国上海市延安西路65号上海国际贵都大饭店办公楼 405 单元

Phone: +86-21-62489820

Fax: $+86-21-62489821$ 
(C) 2012 The Author(s). Licensee IntechOpen. This is an open access article distributed under the terms of the Creative Commons Attribution 3.0 License, which permits unrestricted use, distribution, and reproduction in any medium, provided the original work is properly cited. 